\title{
Physcomitrium patens Mutants in Auxin Conjugating GH3 Proteins Show Salt Stress Tolerance but Auxin Homeostasis Is Not Involved in Regulation of Oxidative Stress Factors
}

\author{
Haniyeh Koochak ${ }^{1,2}$ and Jutta Ludwig-Müller $1, *$ (D) \\ 1 Institut für Botanik, Technische Universität Dresden, 01062 Dresden, Germany; haniyeh.koochak@wsu.edu \\ 2 Institute of Biological Chemistry, Washington State University, Pullman, WA 99164-5910, USA \\ * Correspondence: Jutta.Ludwig-Mueller@tu-dresden.de
}

check for

updates

Citation: Koochak, H.; Ludwig-

Müller, J. Physcomitrium patens

Mutants in Auxin Conjugating GH3

Proteins Show Salt Stress Tolerance

but Auxin Homeostasis Is Not

Involved in Regulation of Oxidative Stress Factors. Plants 2021, 10, 1398. https://doi.org/10.3390/

plants10071398

Academic Editor: Wendy Ann Peer

Received: 25 May 2021

Accepted: 7 July 2021

Published: 8 July 2021

Publisher's Note: MDPI stays neutral with regard to jurisdictional claims in published maps and institutional affiliations.

Copyright: (c) 2021 by the authors. Licensee MDPI, Basel, Switzerland. This article is an open access article distributed under the terms and conditions of the Creative Commons Attribution (CC BY) license (https:// creativecommons.org/licenses/by/ $4.0 /)$.

\begin{abstract}
Salt stress is among the most challenging abiotic stress situations that a plant can experience. High salt levels do not only occur in areas with obvious salty water, but also during drought periods where salt accumulates in the soil. The moss Physcomitrium patens became a model for studying abiotic stress in non-vascular plants. Here, we show that high salt concentrations can be tolerated in vitro, and that auxin homeostasis is connected to the performance of $P$. patens under these stress conditions. The auxin levels can be regulated by conjugating IAA to amino acids by two members of the family of GH3 protein auxin amino acid-synthetases that are present in P. patens. Double GH3 gene knock-out mutants were more tolerant to high salt concentrations. Furthermore, free IAA levels were differentially altered during the time points investigated. Since, among the mutant lines, an increase in IAA on at least one $\mathrm{NaCl}$ concentration tested was observed, we treated wild type (WT) plants concomitantly with $\mathrm{NaCl}$ and IAA. This experiment showed that the salt tolerance to $100 \mathrm{mM} \mathrm{NaCl}$ together with 1 and $10 \mu \mathrm{M}$ IAA was enhanced during the earlier time points. This is an additional indication that the high IAA levels in the double GH3-KO lines could be responsible for survival in high salt conditions. While the high salt concentrations induced several selected stress metabolites including phenols, flavonoids, and enzymes such as peroxidase and superoxide dismutase, the GH3-KO genotype did not generally participate in this upregulation. While we showed that the $\mathrm{GH} 3$ double $\mathrm{KO}$ mutants were more tolerant of high $(250 \mathrm{mM}) \mathrm{NaCl}$ concentrations, the altered auxin homeostasis was not directly involved in the upregulation of stress metabolites.
\end{abstract}

Keywords: auxin conjugation; moss; oxidative stress markers; Physcomitrium patens; salinity stress

\section{Introduction}

Salt stress is among the most challenging situations in many areas worldwide for plant growth and development [1] since it results in both osmotic and drought stress conditions for a plant [2]. In general, mosses seem to be quite tolerant to salt stress. The moss Physcomitrium (recently renamed from Physcomitrella [3]) patens has become a model to study abiotic stress situations in non-vascular plants $[4,5]$. Drought stress responses have been studied extensively including the role of abscisic acid (ABA) [4]. In addition, it was shown that $P$. patens is influenced by salt [4] and high temperature [6], both showing crosstalk between the signaling molecules and also biotic stress factors $[7,8]$. The abiotic stress response of $P$. patens has been investigated on the transcriptome [4,9,10], proteome [11], and metabolome level [5]. Studies report that P. patens survives moderate osmotic and salt stress [4,12], and this tolerance is similar to that found for other moss species such as Bryum argenteum and Atrichum undulatum [13], but higher compared to, for example, ferns [13] or the higher plant model Arabidopsis thaliana [4]. Besides ABA, the auxin indole-3-acetic acid (IAA), plays a role in the salt stress response of plants [14]. During the plant life cycle, auxin is involved in a variety of growth responses and developmental processes, which are regulated in a concentration dependent manner involving the formation of auxin 
conjugates [15]. Conjugate formation is catalyzed by a family of IAA amino acid conjugate synthetases, of which P. patens has two members [16]. IAA conjugates and their hydrolysis might play a role in abiotic stress responses [15]. For example, in P. patens light and high temperatures adversely regulate the response in GH3 double $\mathrm{KO}$ mutants [17]. During salt stress, this has not yet been studied in $P$. patens, but a role for auxin conjugates has been reported in Populus tremula [18], Brassica rapa [19], and A. thaliana, and in the latter the overexpression of the $P$. tremula auxin conjugate hydrolase rendered the plants more tolerant of high salt [20].

The regulation of the IAA homeostasis in non-vascular plants seems to be dependent on synthesis, degradation, and to lesser extent also conjugation with small molecules resulting in inactivation $[21,22]$, while in vascular plants the conjugation and hydrolysis of the conjugates contribute to auxin homeostasis to a larger extent [15]. In P. patens, the conjugation has been described [16] and it seems that it also has the capability to hydrolyze the conjugates back to free IAA [23]. However, several lines of evidence presented point to a horizontal gene transfer from bacteria for the genes identified so far [23]. In liverworts, conjugation and hydrolysis is most likely taking place already via conjugation and hydrolysis, according to the genes annotated in the respective genomes [24,25]. In contrast to the hydrolase present in P. patens, in Marchantia polymorpha a precursor enzyme of the vascular plant type has been identified [25]. Which conjugates are present in P. patens has, to our knowledge, not yet been elucidated, but for other moss species the occurrence of mainly IAA-Aspartate in low concentrations was described [26]. The conjugates present in $P$. patens may be inferred from by the substrates used and conjugates made in vitro and in planta [16]. While $P p G H 3-1$ conjugated only two amino acids (alanine and aspartate) to IAA, $P p G H 3-2$ had a broader substrate range in terms of amino acids. In planta the conversion of IAA added to the cultures resulting in the synthesis of IAA-Valine, IAA-Phenylalanine, and IAA-Leucine/Isoleucine, but not of conjugates with alanine or aspartate [16]. The hydrolases were able to cleave IAA conjugates with alanine, glycine, leucine/isoleucine, phenylalanine, and to a small extent valine in vitro [23], so the capability to synthesize and cleave IAA conjugates in P. patens seems partially to match. In planta IAA-Alanine and IAA-Glycine were cleaved, but since these hydrolases have not been expressed in publicly available databases, their role is still enigmatic.

In addition, a biosynthetic pathway, most likely via indole-3-pyruvic acid (IPyA) as the main intermediate [27], was reported due to the presence of genes known from $A$. thaliana to convert IPyA (TAA, YUCCA) [28]. The transport of IAA in mosses such as P. patens was described in [29] based on the occurrence of genes encoding influx [28] and efflux carrier proteins [30]. Export would result in a direct reduction through the small tissue layers of, e.g., leaves [31]. The existence of a degradation pathway has also to be considered, especially since Stzein et al. [21] indicated a degradation pathway for IAA. The existence of proven IAA oxidase enzymes in $A$. thaliana $[32,33]$ will make it easier to identify whether these are present in P. patens or if another strategy to degrade IAA is used.

Other typical stress metabolites include sugars such as trehalose [5], phenols [20], flavonoids [34,35], ROS and ROS detoxifying enzymes such as peroxidase (POX) and superoxide dismutase (SOD) [36]. In general, the phenolic and flavonoid biosynthetic pathways are considered conserved in nature, therefore mosses already make use of these stress compounds $[37,38]$. In P. patens, for example, UV-B treatment can induce flavonoid biosynthesis [38]. Among the phenols, phenolic acids can accumulate under salt stress and detoxify ROS due to their antioxidative potential [20]. Additionally, lipid peroxidation as a result of the presence of ROS can be determined as the amount of malondialdehyde present in tissues [19]. While there are many roles assigned to peroxidase isoenzymes, one major one is in stress protection [39]. Both antioxidative enzymes POX and SOD are important for the scavenging of ROS [34,39].

Many studies report that P. patens survives osmotic and salt stress (e.g., [4,12]). Therefore, the aim of this study was to continue the investigation into the role of auxin homeostasis in P. patens by using the previously published GH3 double KO lines [16] and expose 
these together with WT to different salt concentrations. This should broaden the knowledge already available for $P$. patens under salt stress [4-6,9,12], but focusing on a possible role for auxin in this scenario. Since all mutants were generated based on homologous recombination and are all true knockout lines [16], the effects that we observed might be due to alterations in the lines due to possible long cultivation periods. While we showed that the $\mathrm{GH} 3$ double $\mathrm{KO}$ mutants were more tolerant concerning some phenotypical parameters at high $(250 \mathrm{mM}) \mathrm{NaCl}$ concentrations, the altered auxin homeostasis was not directly involved in the upregulation of stress.

\section{Results}

\subsection{Growth of Physcomitrium patens at High Salt Concentrations and Revival}

One hundred $\mathrm{mM} \mathrm{NaCl}$ is considered moderate salt stress in P. patens since exclusion of Na via sodium ATPase (PpENA1) ensures normal growth of P. patens under moderate salt stress [40], but higher concentrations in experiments with $P$. patens have also been reported [4]. To set up a test system, we have included not only low, but also very high salt concentrations. At $500 \mathrm{mM} \mathrm{NaCl}$, bleaching of leaves was observed three weeks after transfer to salt medium (Figure 1A), whereas at $250 \mathrm{mM} \mathrm{NaCl}$ the plants were still viable after even 50 days (see also Figure 2). However, this was mainly due to green protonema, whereas the gametophores also showed bleached leaves. Therefore, we hypothesize that the protonema tissue is less sensitive to high salt concentration and might be regarded as the duration tissue. It was possible to revive the gametophores from $250 \mathrm{mM} \mathrm{NaCl}$ (Figure 1B), but not from $500 \mathrm{mM}$ (data not shown). Three weeks after transfer to control media, new gametophores developed and were green. The gametophores showed survival at up to $500 \mathrm{mM} \mathrm{NaCl}$, at least for two weeks (Figure 1A). The survival was for a longer time period (up to 50 days after transfer colonies were still green, even though they did not show any more growth; Supplementary Materials Figure S1). Individual gametophores showed greening of the formerly whitish parts.

A

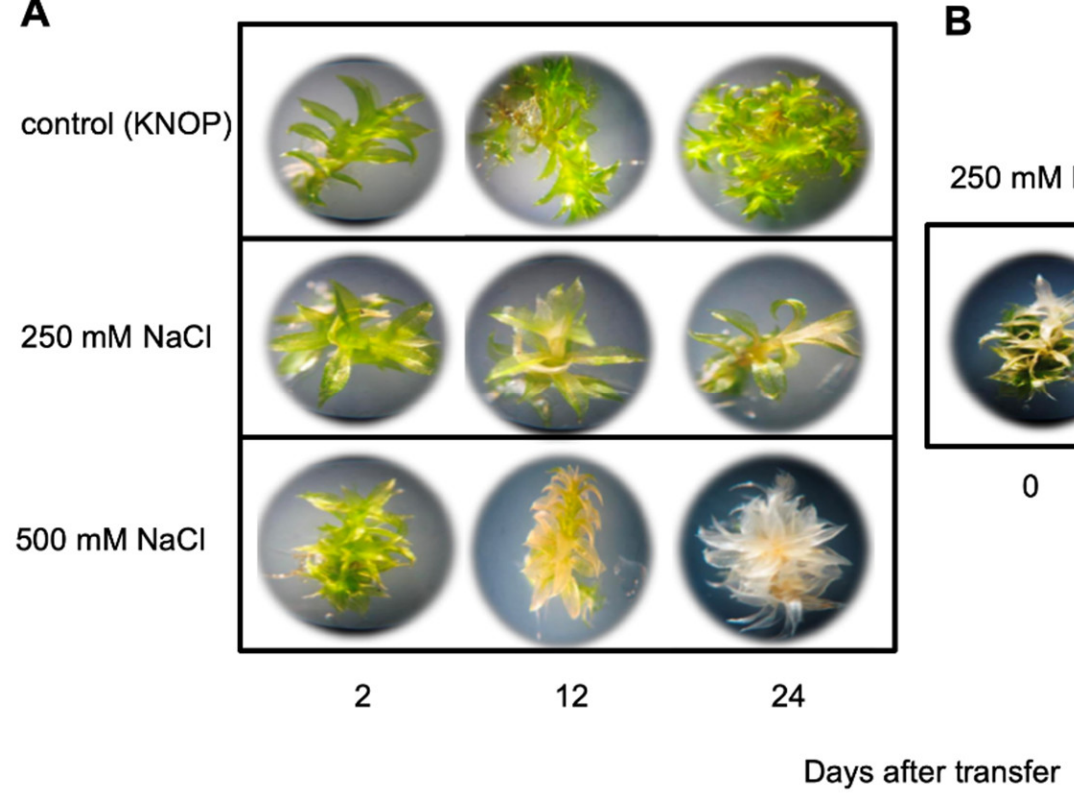

Figure 1. Growth of P. patens gametophores on medium containing high salt concentrations: (A) Individual gametophores are shown that have developed for 2, 12, and 24 days on either control medium without salt or on $250 \mathrm{mM}$ and $500 \mathrm{mM}$ $\mathrm{NaCl}$; (B) Individual gametophores were transferred after 3 weeks from $250 \mathrm{mM} \mathrm{NaCl}$ to medium without salt and were photographed 7 and 14 days after transfer. In panel (B), at each time point the same plant was photographed. 

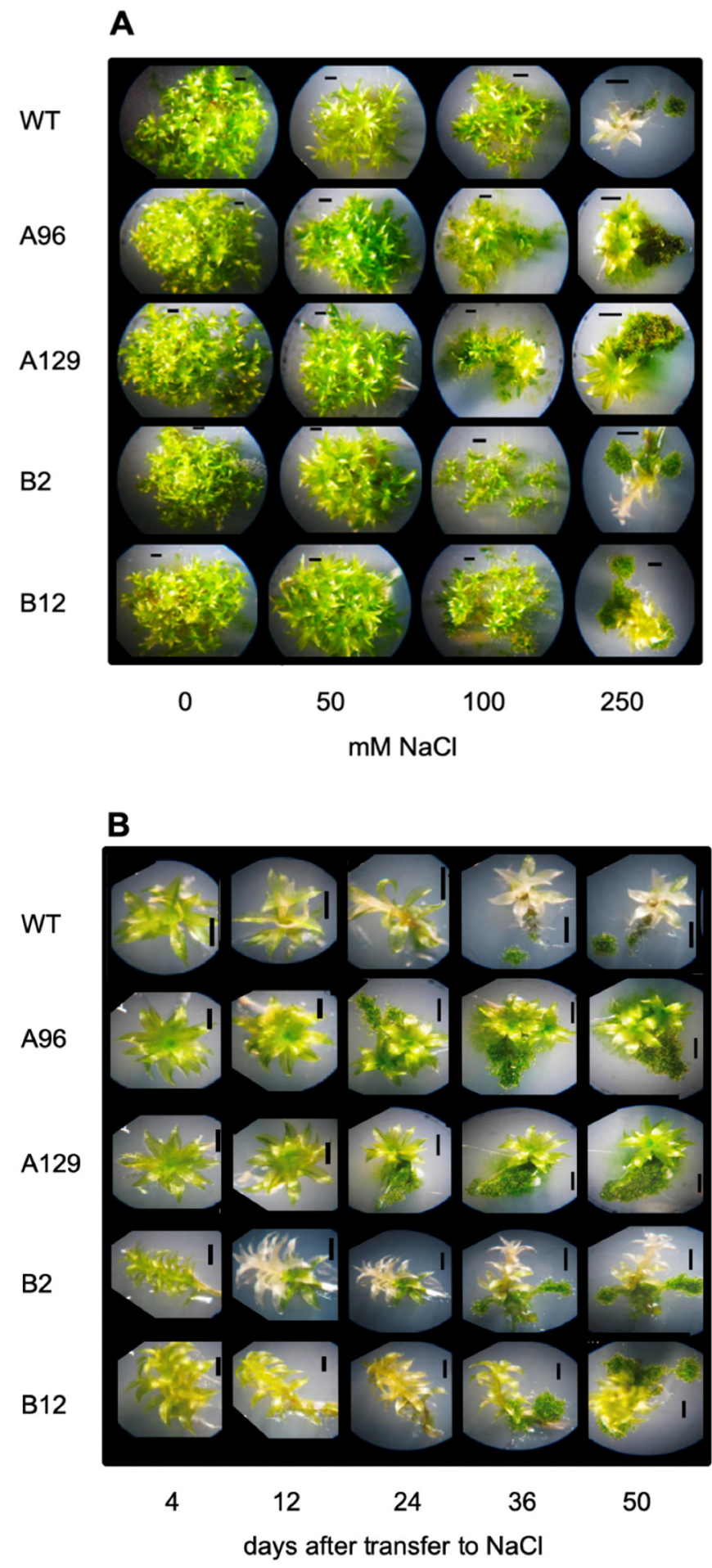

Figure 2. The growth of $P$. patens WT and four different double knock-out mutants in the two GH3 genes:.(A) Different $\mathrm{NaCl}$ concentrations 50 days after transfer to salt-containing media. (B) Time course on $250 \mathrm{mM} \mathrm{NaCl}$. Selected colonies are shown here in magnification. The pictures of the complete plates under the same conditions are shown in the supplement.

\subsection{Digital Expression Analysis Showed That P. patens GH3 Genes Are Differentially Expressed} during Abiotic Stress

Digital transcription analysis of the two $P p G H 3$ genes under various stress conditions was monitored using available web resources (Phytozome, GeneAtlas, Thermo Fisher Scientific, Dreieich, Germany) [41,42] and GFP browser [43,44]. Since desiccation tolerance can be induced by exogenous ABA [45,46], ABA treatment was also included in this analysis. 
Upon dehydration, both GH3 genes are strongly downregulated in gametophore tissues, but ABA treatment resulted in the upregulation of $P p G H 3-2$, but not $P p G H 3-1$ in protonema cultures (Figure 3A). This difference could possibly be explained by a promoter element present that would not respond to ABA. Dehydration resulted in a down-regulation of both $P p G H 3$ gene transcripts, whereas salt stress only led to a downregulation of $P p G H 3-2$ in a different web-resource (Figure 3B). In addition, the GH3 genes from P. patens are also developmentally regulated (data not shown; from $[43,44]$ ).

A
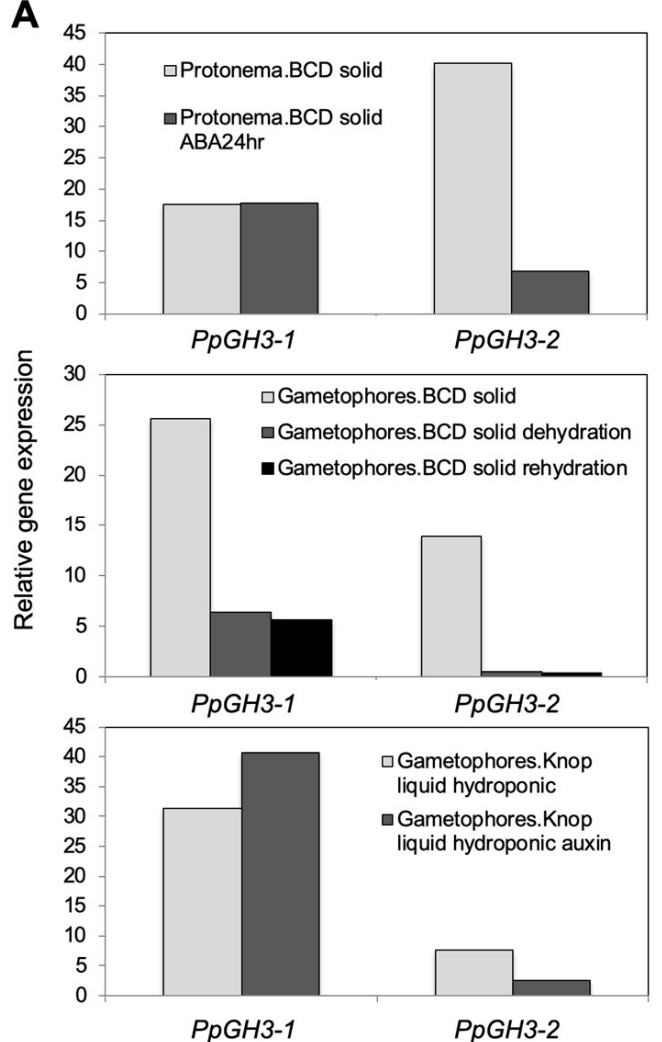

B

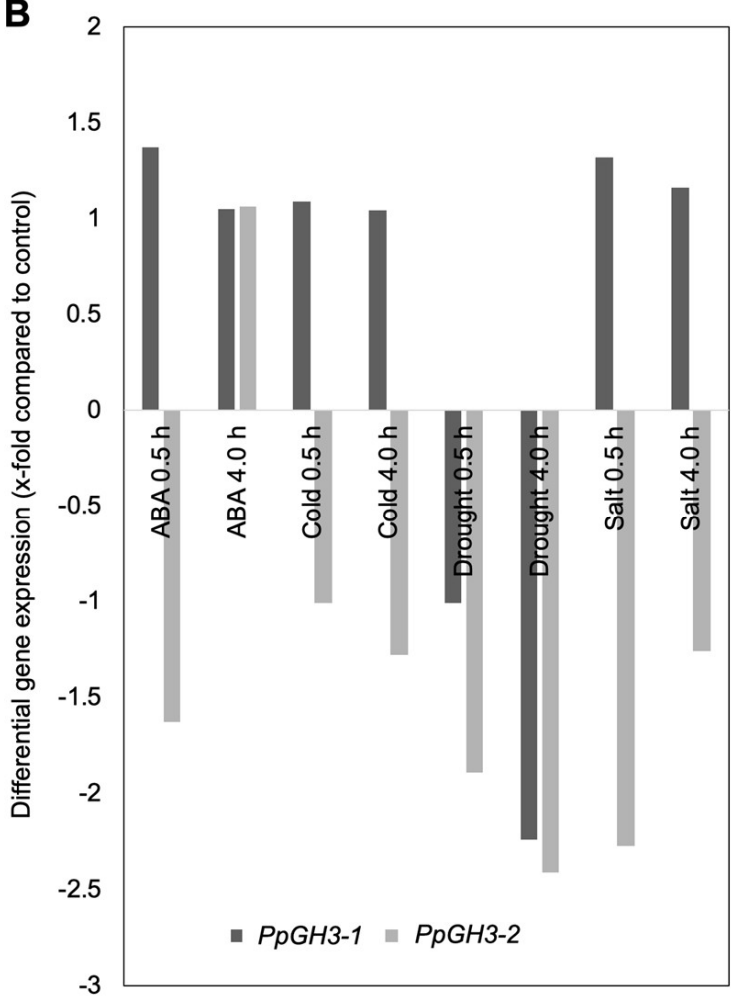

Figure 3. Selected samples from digital gene expression analysis of both GH3 genes using published data from Gene Atlas (Phytozome) [41,42] (A) and eFP browser [43,44] (B).

The promoter sequences of both GH3 genes were analyzed for the occurrence of possible regulatory elements circa $3 \mathrm{~kb}$ upstream of the transcription start, but regulatory elements such as TATA- or CAAT-boxes were not included (Table S1; from Phytozome [40]. Function of the element and element names are given, as well as the number of the elements in the respective promoter region (in brackets). Only the promoter of PpGH3-1 has elements that were assigned to ABA inducibility. Both have an element that is assigned to be responsible upon drought. Interestingly, the promoters both do not have obvious predicted auxin-response elements. This is in accordance with digital gene expression levels of gametophores after auxin treatment (Figure 3A).

\subsection{PpGH3 Double KO Mutants Show More Tolerance to Growth on High Salt}

Since it is known that IAA homeostasis plays a role in salt stress responses in different plant species such as $A$. thaliana and P. tremula [17], and the GH3 proteins of P. patens seem to be involved in other stress responses, we investigated whether the previously described double knock-out mutants $[7,15,16]$ show altered phenotypes in comparison to WT. The gametophore phenotype after salt stress was analyzed and it was found that the gametophores of all mutant lines showed a retardation in bleaching of the leaves at higher $\mathrm{NaCl}$ concentrations. In addition, the protonema was taking up larger areas on the plates, so that the total growth diameter of the mutants was higher than WT (Figure 2). All 
GH3 double mutants were more tolerant to salt stress as shown after 50 days of transfer to $250 \mathrm{mM} \mathrm{NaCl}$ (note the WT photo is the same as in Figure 1).

In comparison to the scattered growing protonema on $100 \mathrm{mM} \mathrm{NaCl}$, the colonies on $250 \mathrm{mM} \mathrm{NaCl}$ have darker green, smaller, and denser protonema with a slower growth rate. The mutant lines in particular show an extended protonema growth compared to WT (Figure 2), which is indicative of a possible protective role for the protonema tissue for stress tolerance. However, the fresh weight under these conditions was not significantly different between WT and the mutant lines (Figure S2). A more detailed analysis including the growth rate showed that especially two lines were significantly more tolerant while two others were not (Figure 4). Since the mutant lines are all generated via homologous recombination, differences between lines cannot be explained by the genetic background, but rather by alterations that must have occurred during the long cultivation period between mutant generation and experimental period. In future experiments this can be addressed by, e.g., transcriptome analyses.

A
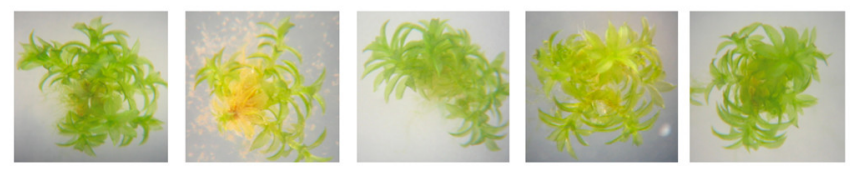

control
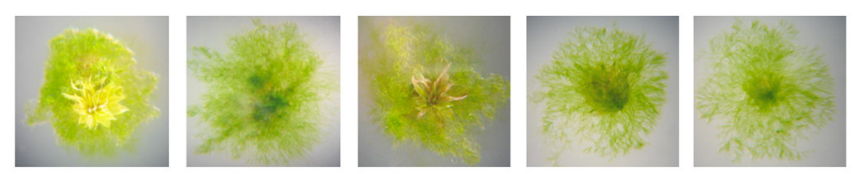

$100 \mathrm{mM} \mathrm{NaCl}$

\section{B}

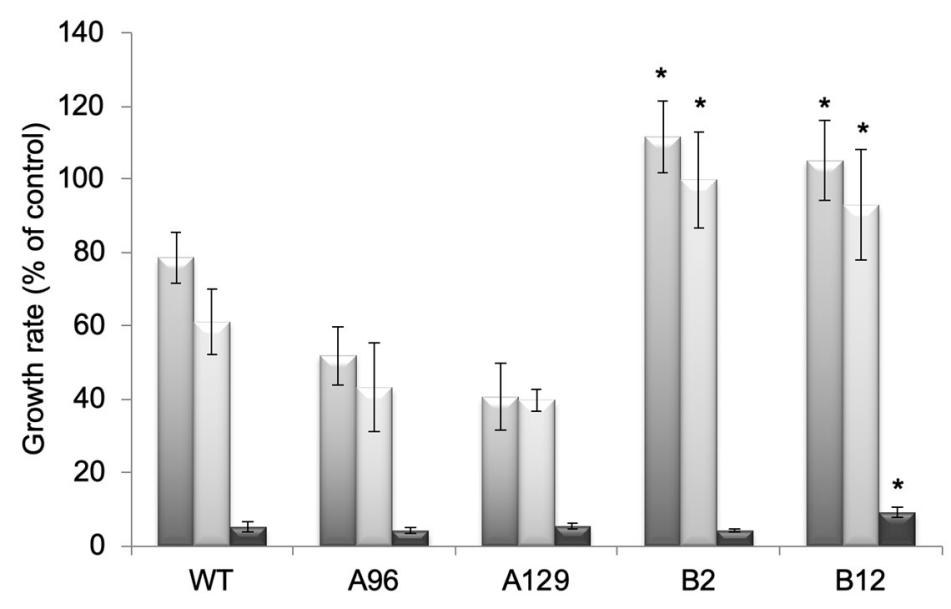

$\mathrm{NaCl}(\mathrm{mM})$

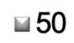

$\square 100$

$\square 250$

Figure 4. Growth of protonema is promoted on high salt concentrations, which results in accelerated growth rates: (A) Examples of WT and GH3 double $\mathrm{KO}$ lines on control medium and medium containing $100 \mathrm{mM} \mathrm{NaCl}$; (B) The growth rate of the same lines on 50, 100, and $250 \mathrm{mM} \mathrm{NaCl}$ determined as percent of the control without $\mathrm{NaCl}$ over the time of 50 days after transfer to saltcontaining medium. The asterisks indicate significant differences between WT and mutant lines at $p<0.05$.

The water loss calculated from the ratio dry weight to fresh weight was also not significantly changed when WT was compared with two mutant lines at different salt concentrations (Figure S3). These observations confirm that the loss in auxin conjugation does not alter growth per se, but the ratio of gametophytes vs. protonema might be altered. This supports the observation that the protonema tissue mainly responded to salt stress, which is a minor fraction of the weight of the plant. The quantification of protonema growth alone is difficult due to the irregular shape of the colonies.

In addition, free IAA was determined in the samples grown on $0,50,100$, and $250 \mathrm{mM}$ $\mathrm{NaCl}$ over a period of 12 to 36 days after transferring gametophores from control medium. The data were expressed on the basis of the control treatment $(0 \mathrm{mM} \mathrm{NaCl})$ for each line 
and time point. Using this type of calculation, the differences for the individual lines can be better seen. While the replicates had high variations, nevertheless differences in free IAA were detectable. During the course of the experiment (12, 24, and 36 days at 50, 100, and $250 \mathrm{mM} \mathrm{NaCl}$ ) an increase in the free IAA content at 12 days was observed only for one $\mathrm{KO}$ line, but after 24 days three out of four mutant lines showed a significant difference to WT in the IAA levels for at least one salt concentration, while after 36 days the effect was no longer significantly different (Figure 5). Therefore, the increase in free IAA might be one of the factors responsible for the tolerance of the $\mathrm{GH} 3$ double-KO lines. Additional possibilities would be that higher auxin levels are indirectly responsible for the tolerant phenotype of the mutants as a result of a delay in senescence. The greener leaves of mutant lines compared to WT at high salt levels would fit into this hypothesis (Figure 2).

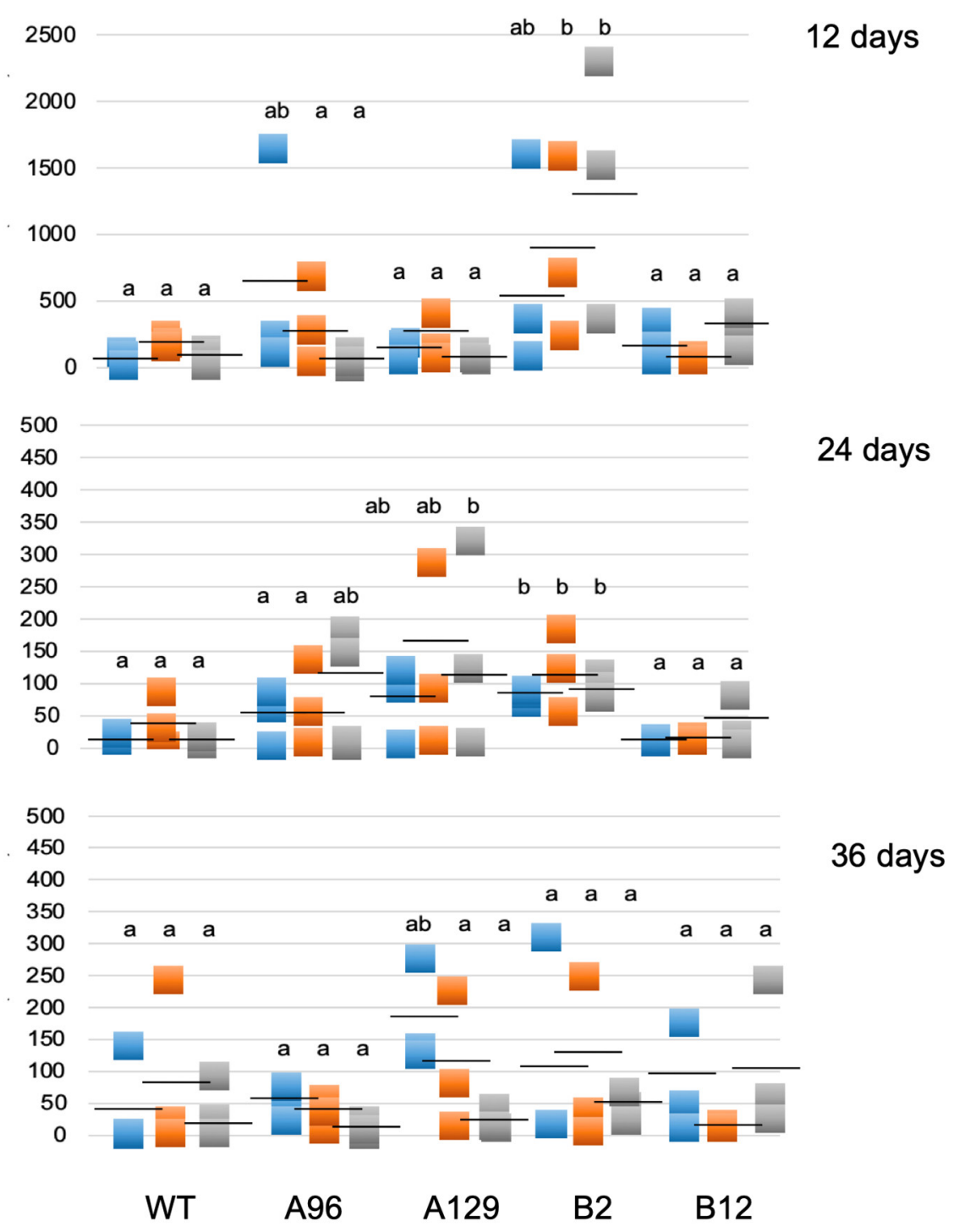

Figure 5. Free IAA levels given as $\%$ on control medium $(0 \mathrm{mM} \mathrm{NaCl})$. Blue $=50 \mathrm{mM} \mathrm{NaCl}$; orange $=100 \mathrm{mM} \mathrm{NaCl}$; grey $=250 \mathrm{mM} \mathrm{NaCl}$. The IAA was determined at three different time points for three replicates. Different letters indicate significant differences to the control without $\mathrm{NaCl}$ at $p<0.05$. Each square represents an individual data point and the black dash represents the mean value.

To test this assumption, WT plants were treated with $100 \mathrm{mM} \mathrm{NaCl}$, where the growth was positively affected for two mutant lines (Figure 4), concomitantly with two different IAA concentrations $(1$ and $10 \mu \mathrm{M})$. Since free IAA levels were under some conditions higher 
on salt in the mutants compared to WT, this experiment should mimic the conditions in the mutant lines. The treatment of WT moss with 1 and $10 \mu \mathrm{M}$ IAA showed that the growth phenotype could be phenocopied to some extent (Figure 6). The growth rate as a percent of control between 0 and 36 days was determined as the diameter of three time intervals at which the measurements were done (Figure 6A) and the fresh weight of all colonies was determined after 36 days on media (Figure 6B). Based on the calculations described in detail in the legend to Figure 6, values for the IAA treatments that are higher than the control value are an indication of the moss plants performing better on simultaneous $\mathrm{NaCl}$ and IAA treatments. For the first two time points there were differences between WT with $\mathrm{NaCl}$ and IAA compared to WT with only $\mathrm{NaCl}$. However, this trend was not visible any more at later times, which ended after 36 days with $\mathrm{NaCl}$ and for which the fresh weight was also determined. Like for the resistant mutant lines (Figure S2), the fresh weight was not an indication of stress tolerance. This might again be due to the involvement of protonema in growth responses, which do not contribute significantly to the weight of the overall culture (Figures 4 and 6).

A

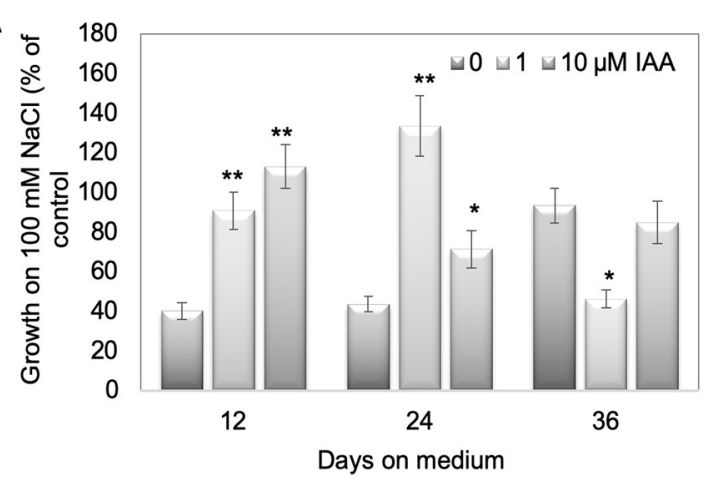

B

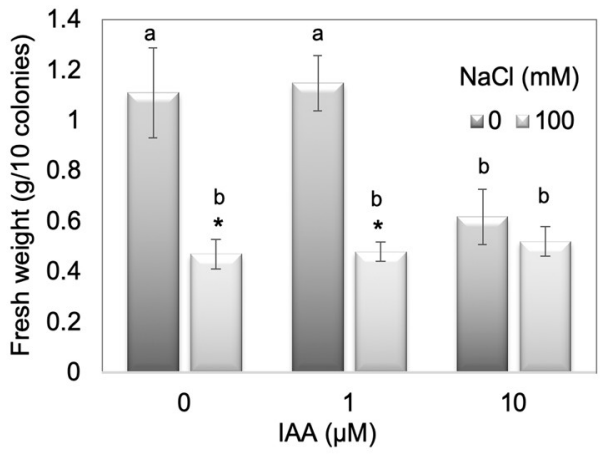

Figure 6. IAA $(1$ and $10 \mu \mathrm{M})$ treatment of WT together with high salt concentration $(100 \mathrm{mM})$. (A) Growth rate as percent of control between 0 and 36 days given as diameter of three time intervals at which the measurements were done and (B) fresh weight after 36 days was recorded. In (A,B), the mean values for 12 plates with 10 colonies on each plate are given. Asterisks in (A) denote statistically significant differences between control and IAA treatments on $100 \mathrm{mM} \mathrm{NaCl}$ expressed as percentage of the control, in (B) denote statistically significant differences between control and $\mathrm{NaCl}$ treatment $\left({ }^{*} p<0.05\right.$, $\left.{ }^{* *} p<0.01\right)$, and different letters in (B) indicate differences between control and IAA treatments. Calculations for growth rate in (A) were done by measuring the diameter of colonies at 0 days (day of transplanting on fresh medium), diameter of colonies at 12, 24, and 36 days on treatment medium and subtracting the respective later time point from the earlier one. The value for 12 days is thus the difference/growth rate between day 0 and day 12, the value for 24 days growth between 12 and 24 days, and the value for 36 days represents the growth between 24 and 36 days. To show the effect of $\mathrm{NaCl}$ compared to control, for each value +/ - IAA the percentage of growth on $100 \mathrm{mM} \mathrm{NaCl}$ compared to the control was calculated. Values higher than the control value without IAA are an indication that the moss plants are performing better on simultaneous $\mathrm{NaCl}$ and IAA treatments.

2.4. Salt Stress Upregulates Different Stress Parameters in Gametophores, but PpGH3 Proteins Are Not Involved in Their Upregulation

The response to abiotic stress involves an increase in low molecular weight scavenging molecules and enzymes since the stress might result in the generation of reactive oxygen species (ROS). Therefore, different stress-related parameters were assessed to evaluate which stress response might be upregulated in mutants compared to WT. Here, total phenols, lipid peroxidation, flavonoids, as well as peroxidase and superoxide dismutase enzyme activities were tested. Flavonoids are not only stress-induced compounds, but also modulate auxin transport [47]. We found, with very few exceptions, no genotype specific differences between WT and mutants, but differences in the WT response to salt stress were observed. In addition, twelve days after treatment not many effects were found, so the data are in most cases given for 24 and/or 36 days after transfer to salt-containing media. 
The complete dataset for all time points, $\mathrm{NaCl}$ concentrations, and genotypes can be found in the Supplementary Materials (Figures S4, S6 and S7).

Bryophytes contain only flavonoids synthesized early in the phenylpropanoid pathway, that is naringenin chalcone and naringenin, dihydrokaempferol and kaempferol, and dihydroquercetin and quercetin [48-50]. A gene for narigenin chalcone synthesis is annotated in the KEGG (Kyoto Encyclopedia of Genes and Genomes, Kyoto, Japan) database for P. patens (Figure S5). During stress response (UV light), a band corresponding to a quercetin derivative was detected in P. patens leaves by thin layer chromatography [34]. Flavonoids were determined in this work also with diphenylboric acid 2-amino-ethyl-ester (DPBA) that binds to flavonoids enabling their in situ visualization. The DPBA-flavonoid complex will show a specific fluorescence color depending on the structure of the respective flavonoid and is therefore specific [51]. Since there were no differences between the mutant lines and $\mathrm{WT}$, only WT leaves are shown for three different $\mathrm{NaCl}$ concentrations for all three time points (Figure 7). Two gametophores were randomly picked for the photographs (Figure 7). The yellow-orange colored leaves contain quercetin and Q-derivatives, such as the glycoside rutin [51-53]. The cyan color stands for naringenin, green for kaempferol, blue for sinapate derivatives, and red is the chlorophyll autofluorescence [51-53]. The group of quercetin derivatives seems to decrease over time and with salt stress. Naringenin is present in all samples, whereas kaempferol could only be detected in a few spots. Sinapate derivatives are more present at higher salt concentrations.
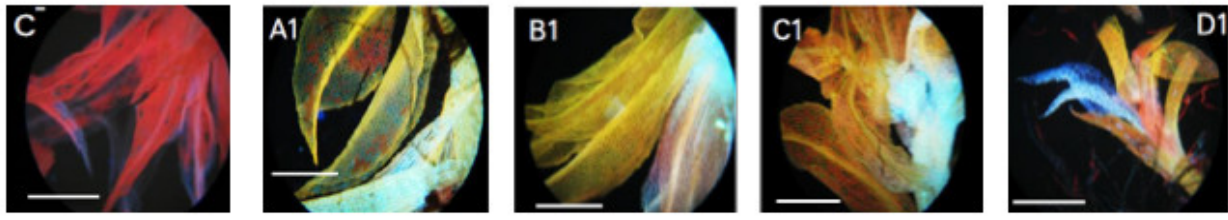

12 days
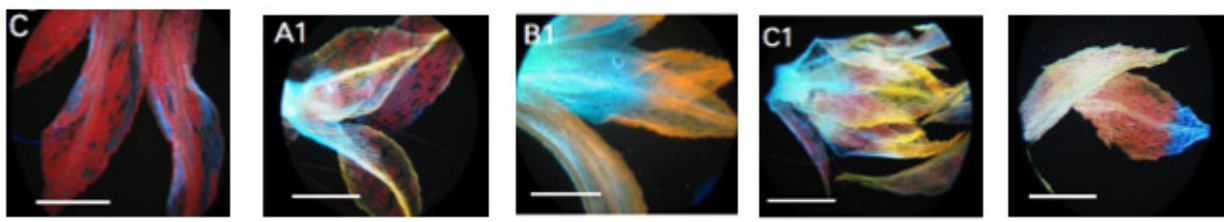

24 days
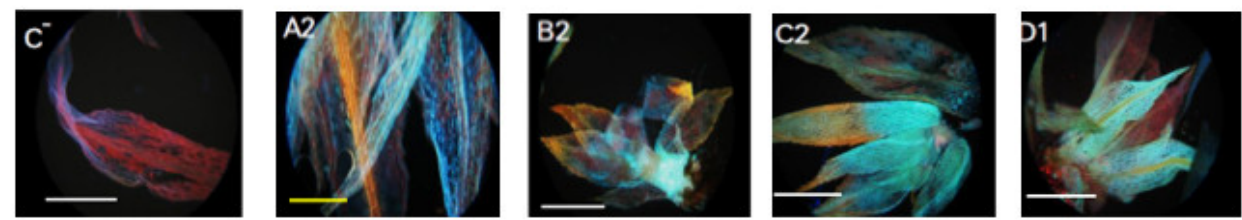

\section{6 days}

neg.

0

50

100

250

$\mathrm{mM} \mathrm{NaCl}$

Figure 7. In situ staining of flavonoids with DPBA according to the method of Buer and Muday [53]. Individual gametophores are shown for the different salt concentrations at three different time points. The first panel is the negative (neg.) control without DPBA $\left(\mathrm{C}^{-}\right)$; mainly showing the red autofluorescence of chlorophyll. Yellow color denotes quercetin derivatives, cyan naringenin derivatives, and green kaempferol derivatives, while blue denotes sinapate derivatives. The negative controls without staining solution show only the red chlorophyll fluorescence. Only one set of pictures for WT is shown for all three time points. All data including two mutant lines are shown in the Supplementary Materials (Figure S6). The bars indicate $100 \mu \mathrm{m}$.

Total phenols showed a significant reduction under salt stress (between controls and $250 \mathrm{mM} \mathrm{NaCl}$ ), but only at later time points (Figure 8A). Lipid peroxidation as a marker for membrane stress was significantly upregulated in P. patens gametophores after salt stress $(250 \mathrm{mM} \mathrm{NaCl})$, again at the two later time points (Figure $8 \mathrm{~B})$. As expected, the longer 
the gametophores remained in high salt conditions, the more lipid peroxidation could be detected.

A

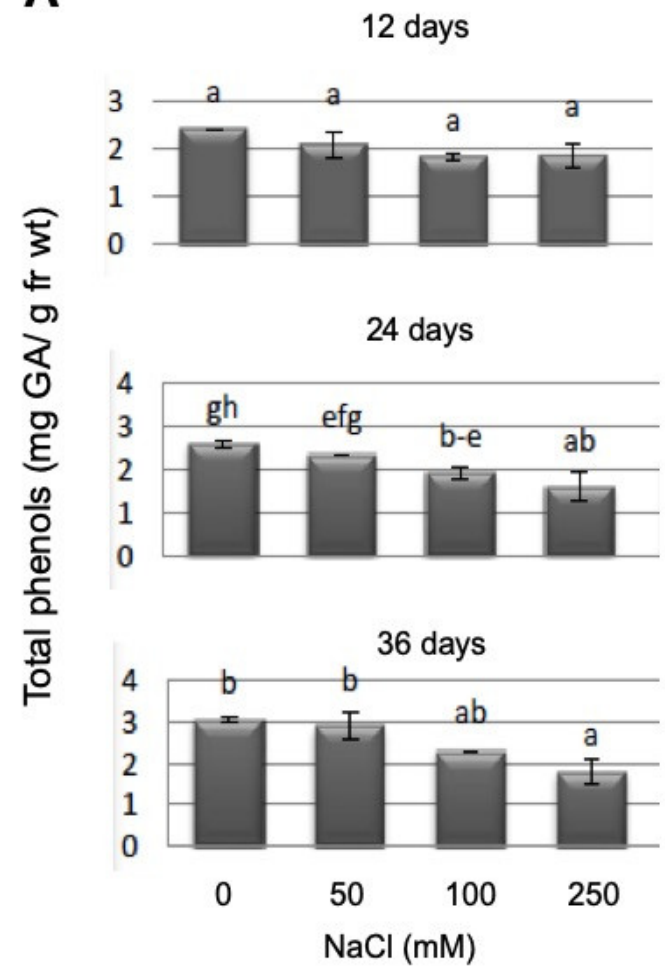

B

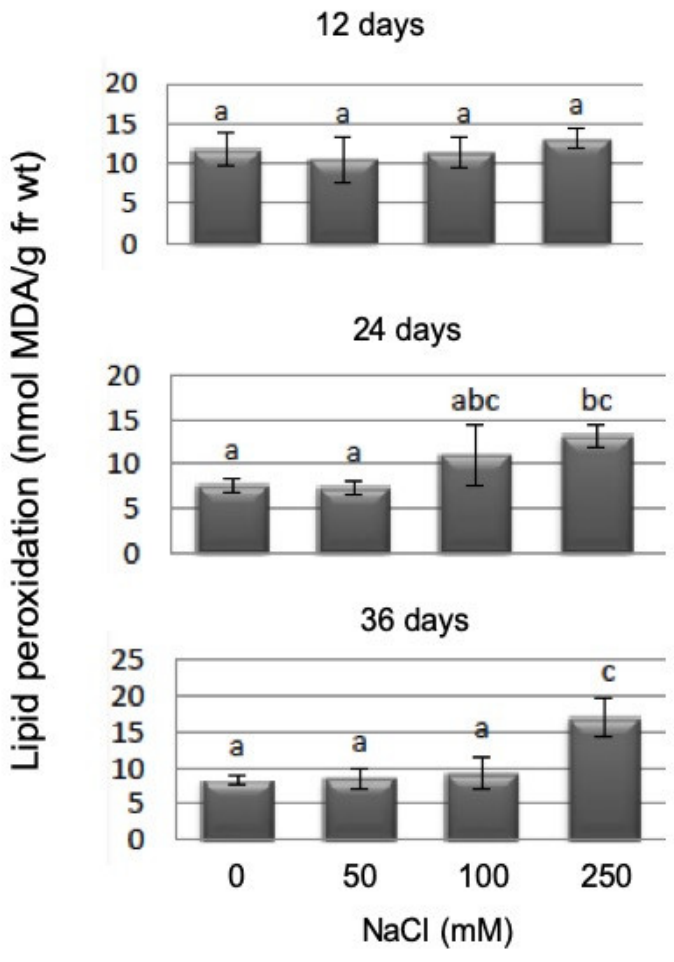

Figure 8. Total phenols determined as gallic acid equivalents (A) and lipid peroxidation as determined as MDA equivalents (B) determined in WT gametophores at different salt concentrations and at three different time points. Bars with different letters are significantly different at $p<0.05$. Since the mutant lines did not show any difference in WT in their response to salt stress with these parameters, the complete dataset is displayed in the supplement.

For total peroxidase activity, significant differences after $250 \mathrm{mM} \mathrm{NaCl}$ treatment were found, which persisted over all measured time points (Figure 9a). Analysis of specific peroxidase isoforms using a native PAGE method [54] showed some quantitative differences between the treated WT and mutant plants, being the only detectable differences in the whole dataset (Figure 9b). All bands increased in intensity in the salt treated samples of WT and mutants, and an increase in a set of isoenzymes with high molecular mass (marked by asterisks) was found that was higher in the two mutant lines than in the WT. The complete dataset is shown in the Supplementary Materilas (Figure S6).

For superoxide dismutase the differences in isoenzyme patterns that can also be visualized on native PAGE by activity stain $[55,56]$ were mainly visible between control and salt treatments, but not between genotypes (Figure 10). There were only slight increases in three different bands and one additional band was found in one of the mutants (B12) (marked by asterisks). The complete gel pictures including the Coomassie stained gel for total protein are shown in the Supplementary Materials (Figure S7). 
a

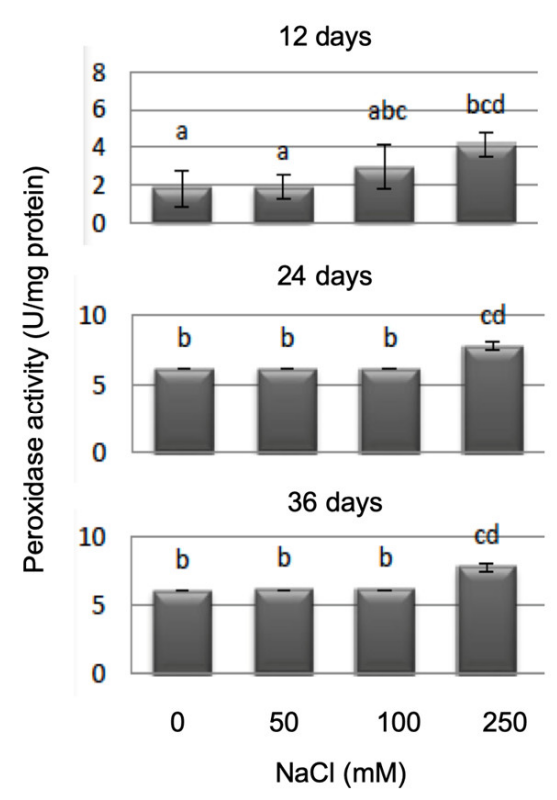

b

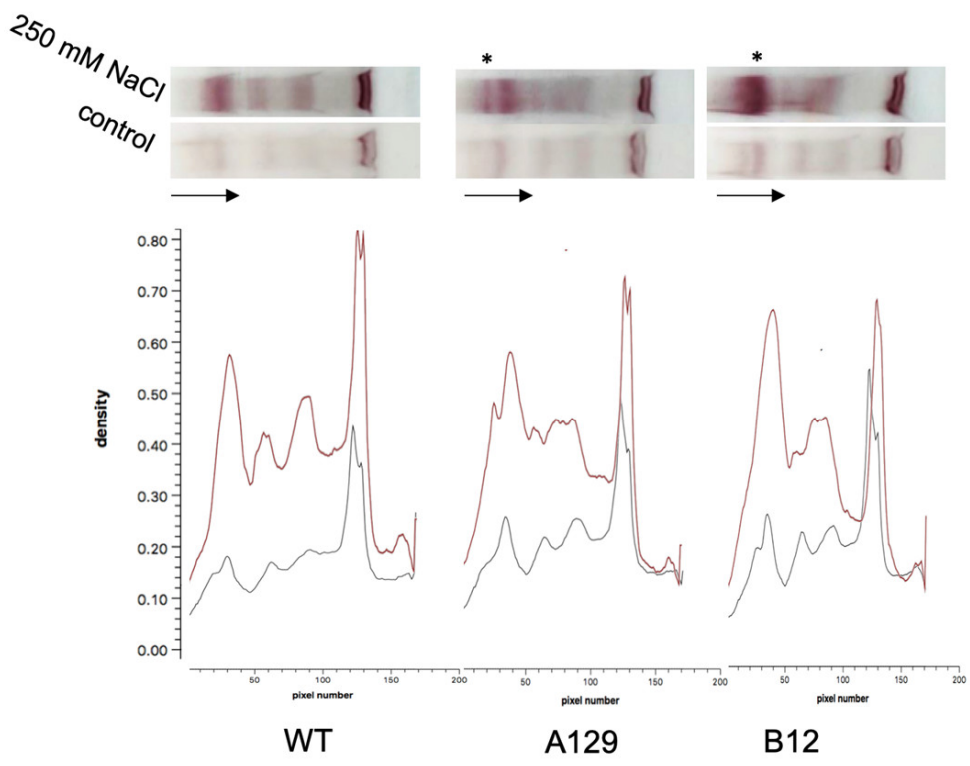

control

$250 \mathrm{mM} \mathrm{NaCl}$

Figure 9. Peroxidase activity of WT determined with OPD (a) and isoenzyme separation of WT and two mutant lines on native polyacrylamide gels using benzidine-guaiacol for visualization (b). Bars with different letters are significantly different at $p<0.05$. Since the mutant lines did not show any difference to WT in their response to salt stress with the parameters determined in (a), the complete dataset including the gel stained with Coomassie blue is displayed in the Supplementary Materials (Figures S4 and S7). The density of the bands in (b) was detected using the GelEval software free trial version 1.35 (FrogDanceSoftware, Cambridge, UK). The asterisks mark differences between WT and mutant lines in the peroxidase isoenzyme pattern. The arrows show the direction of sample flow.

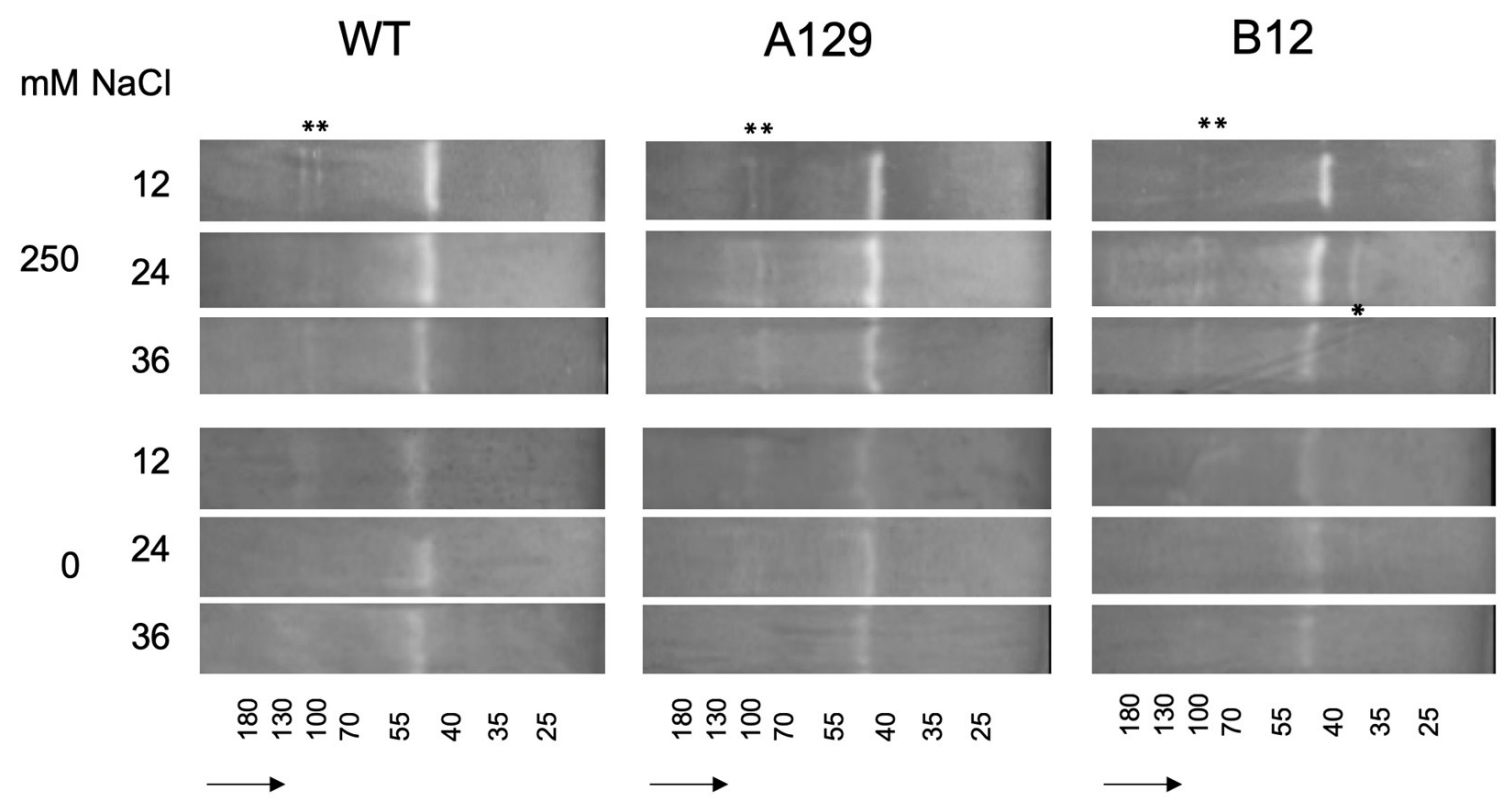

Figure 10. Superoxide dismutate (SOD) isoenzyme separation shown for two selected mutant lines in comparison to WT. Asterisks mark differences between WT and mutant control samples and $250 \mathrm{mM} \mathrm{NaCl}$. For mutant line B12 an additional band is marked. The complete gels including the gel stained with Coomassie blue are shown in the Supplementary Materials (Figure S6). The small numbers at the bottom indicate the approximate molecular masses from marker mixtures. The arrows show the direction of sample flow. 


\section{Discussion}

The majority of plant species cannot endure high concentrations of salt, which causes ion imbalance and hyperosmotic stress and adverse effects following that. In comparison with other plants such as $A$. thaliana, P. patens exhibits a high degree of abiotic stress tolerance. This characteristic makes it invaluable for use in investigations into the identification of genes related to stress adaptation [4]. The identification of salt signaling components and transcription factors in bryophytes suggested that salt stress can lead to activation of adaptive responses and that bryophytes are able to tolerate salt stress by means of multiple biochemical pathways $[4,9,11,46]$. The salt tolerance of $P$. patens is high compared to other plant species [4].

The work presented here indicates the involvement of auxin homeostasis in the salt tolerance response of $P$. patens. The control of auxin levels is very important for all developmental processes in land plants, and also abiotic stress responses [14]. It is mediated, among other important mechanisms, by the conjugation of the free active hormone to amino acids catalyzed by auxin amino acid conjugate synthetases from the GH3 family [14,57]. Among the abiotic stressors, salt stress is a complex trait that results in many different branches within the response. For example, it affects the osmotic homeostasis and parts of drought stress responses due to reduced water uptake [58]. In addition, the upregulation of some "classical" responses to abiotic stress such as phenols, lipid peroxidation, peroxidase, superoxide dismutase needs to be considered [19,54-56]. However, except for a few data, no correlation was found between the knock-out of auxin conjugation and the induction of stress parameters after growth of moss gametophores with high salt levels. Several studies have reported on free IAA levels and also IAA conjugates during salt stress. In several plant species, such as rice, tomato, and wheat, IAA was reduced [59-61], whereas IAA amino acid conjugates were upregulated in other plant species [62]. However, there are also reports on the contrary response, i.e., in Brassica rapa free IAA was upregulated and some conjugates decreased [63]. Such findings could be confirmed on the transcript level $[18,58,64,65]$. If one could reverse these IAA vs. IAA conjugate levels by introducing or knocking down genes involved in the conjugation/hydrolysis of IAA conjugates, the IAA would increase, and amino acid conjugates decrease in such a mutant. In $A$. thaliana the increase in IAA via overexpression of an IAA conjugate hydrolase increased salt tolerance [17]. Therefore, the intrinsic IAA levels might be one factor to trigger salt stress tolerance. The double GH3 KO mutants of $P$. patens show the same auxin patterns, namely increased IAA and no amino acid conjugates [16]. Based on these predictions the mutant plants could be more tolerant to (salt) stress.

Indeed, a role for the auxin conjugation in P. patens for other abiotic [16] and biotic stressors has previously been shown [7]. High IAA levels were responsible for tolerance during growth in darkness, but on the contrary caused higher sensitivity to elevated temperature stress [16]. Biotic stressors were also affected by the higher IAA levels of the GH3 double KO lines. It was shown that the oomycete Pythium debaryanum inhibited growth at high IAA concentrations in vitro, so the inhibition of disease progression in the GH3-KO lines with higher IAA content could be explained by this [7]. Alternatively, the auxin effect might be indirect since auxin could delay senescence, which is corroborated by the whiter leaves of WT compared to all mutant lines at high salt concentrations (Figure 1). Previously, it was shown that the same lines showed a delay in senescence in darkness, but an accelerated senescence at higher temperatures [17].

It was shown that a large number of transcripts that respond to dehydration were differentially regulated and several a sub-population also responded to exogenous ABA [66]. Khandelwal et al. [67] demonstrated that the P. patens homolog of the A. thaliana gene Abscisic acid Insensitive $3(A B I 3)$ is required for desiccation tolerance to be induced by the application of ABA. A microarray study using an array consisting only of transcription factors compared salt stress and ABA signaling in P. patens [9]. In mosses, ABA and drought induce the differentiation of protonema cells into brachycytes (brood cells), which represent vegetative propagules for survival under adverse environmental conditions [46]. The 
transcriptional regulation, as found in public transcriptome datasets, of both GH3 genes (Figure 3) suggested a possible role within drought or salt stress as well as after treatment with ABA. In addition, the promoters contain several elements related to upregulation of stress (Table S1). We have therefore analyzed the stress tolerance of WT and GH3 double $\mathrm{KO}$ mutant lines under different salt concentrations (moderate to very high).

While investigations with WT are often conducted [4-6,9,11,12], there is no information as to whether there is a direct connection between auxin and salt stress in P. patens. For A. thaliana and other higher plants there is more information [14], for example it was found that overexpression of a poplar auxin amino acid conjugate hydrolase resulted in more salt tolerant plants [17]. The hydrolysis of IAA conjugates also results in the increase of free IAA. Likewise, the GH3 double KO mutants have higher IAA levels when grown on medium supplemented with IAA [15] and under stress [16]. Earlier it was reported that in vitro-cultured moss that were exposed for three days to medium containing increasing concentrations up to $350 \mathrm{mM} \mathrm{NaCl}$ were able to recover themselves, while the samples at $500 \mathrm{mM} \mathrm{NaCl}$ were completely bleached two weeks after treatment [4]. Under our growth conditions, a similar trend, namely the bleaching of samples two weeks after transfer to $500 \mathrm{mM} \mathrm{NaCl}$ and their disability to recover themselves after moving to non-stress conditions was confirmed (Figure 1 and data not shown), while growth at $250 \mathrm{mM} \mathrm{NaCl}$ enabled the moss to be revived, but the colonies were also bleached after longer cultivation times at high $\mathrm{NaCl}$ levels (Figure 1). In addition, all mutant lines looked greener at high $\mathrm{NaCl}$ concentrations for a longer growth period and two showed better growth rates (Figures 3, 4 and S1). The data presented here confirm that the mutant plants are more tolerant to high salt concentrations, and that this was mainly due to the capacity of the protonema to grow further (Figures 3 and 4). Previous work has already pointed out the significant role of protonema in abiotic stress response tolerance (reviewed in [54]). However, the growth effect could only be quantified for the two lines B2 and B12, not for the A mutant lines (Figure 4). Since both mutants are generated by the homologous recombination technology, they are true knockouts without any residual transcriptional activity [15]. Different effects between lines could therefore also not be explained by insertion effects. A possibility exists that other events occurred in these lines independent of the primary mutation event and are not directly connected to the primary phenotype. We have to assume that these line specific effects might have been caused by later changes during the clonal cultivation period of these plants.

Since in the GH3 double KO lines a higher IAA content was described under control conditions $[15,16]$, we hypothesize that the elevated IAA levels could be beneficiaries of stress, so that the respective colonies showed better growth at high salt levels. However, under normal conditions the high IAA is not beneficial for growth [15], and this is the reason why it needs to be tightly controlled by the GH3 proteins also in P. patens. Other stress factors, light and elevated temperature, also resulted in increased free IAA in two GH3 double KO lines as shown in previous work [16]. However, the extent to which that occurs seems to be dependent on the type of stress, so the increase observed for salt treatment could differ for other stressors. The mutant plants were more tolerant at higher temperatures, but not to growth in darkness [16]. When free IAA levels in the mutants were compared under different salt concentrations to WT, a relative increase was found between salt and control medium that increased after 12 days only for one mutant line, after 24 days more lines, while 36 days after treatment the effect was not significant any more (Figure 5). Under salt stress conditions, treatment of WT gametophores concomitantly with IAA and $\mathrm{NaCl}$ resulted in the approximate phenocopy of the mutant growth behavior (Figure 6). While the fresh weight did again not reflect any changes, the colony diameter of those WT plants treated with 1 and $10 \mu \mathrm{M}$ IAA was higher with $100 \mathrm{mM} \mathrm{NaCl}$ compared to the colonies grown without IAA. The increased IAA levels in the GH3 double-KO lines could thus be one reason for their survival with salt. Additionally, in this work, the protonemal growth was in part responsible for the observed phenotype (Figures 3, 4 and 6). The determination of the widest point of the diameter might not exactly reflect colony 
size, so using additional digital software to determine the complete gametophyte area could be useful for future research. Previous publications illustrate that the application of auxin to $P$. patens results in a faster transition from chloronema to caulonema and further maintenance of the desired concentration arrests the development in the caulonema stage [68]. In addition to chloronemal branching, this treatment converts most gametophore tissue into rhizoid cells $[69,70]$. This in turn provides a sufficiently dense protonemal mat that maintains a moist soil (or medium) surface [71]. These observations make auxin an important regulator of this developmental transition and some genes responsible for this transition have been identified [72]. Previous work has also shown that the auxin response under stress was at least partially linked to protonema filaments [16]. Together with our observations for salt stress we can confirm the potential of protonema in the stress tolerance [68-70].

There are other examples where higher conjugation levels, i.e., to the auxin indole-3butyric acid (IBA) in A. thaliana resulted in more stress tolerant plants [73]. On the contrary, $\mathrm{NaCl}$ could also directly reduce IAA levels, e.g., in tomato via an ABA-independent pathway [74]. As mentioned above, in A. thaliana, and other higher plant species, the hydrolysis of auxin conjugates plays a role in homeostasis and stress responses $[14,17,18]$. While the GH3 proteins of $P$. patens are similar in sequence and function to the higher plant enzymes [15], the hydrolysis pathway was thought not to take place at all, since the typical plant sequences for conjugate hydrolases were missing [75]. However, recent work provided experimental evidence for the possible hydrolysis of IAA amino acid conjugates in P. patens as well, since it was found that the moss contained sequences similar to bacterial auxin amidohydrolases [24,76] and its capacity to cleave some conjugates in vivo and in vitro [24]. These sequences were possibly acquired by horizontal gene transfer [76]. Modeling of one protein sequence showed similarity to the respective proteins from A. thaliana [76]. Although as far as we know no one has examined P. patens to determine which auxin conjugate is the native product so far, the most likely of these compounds to be present in vivo may be those described for other moss species [76]. The authors found that the most common moss conjugate was IAA-Aspartate at low concentrations. They concluded that liverworts prefer conjugation as a regulatory scheme while mosses favor degradation strategies to maintain homeostasis. This conclusion is supported by the observation that none of the aforementioned hydrolases was expressed in publicly available databases [40-43].

We conclude that auxin is mediating at least some part of the salt stress response of P. patens, but in almost all cases not via the upregulation of the selected stress metabolites measured in this investigation (Figures S4, S6 and S7). Salt stress can result in an increase in the amount of reactive oxygen species (ROS) within plant cells [77]. These ROS are extremely reactive and will damage different cellular parts, for instance DNA, lipids, and proteins. Any serious imbalance between ROS production and antioxidant defenses can cause oxidative stress in plant cells [77]. Therefore, being tolerant to salinity is related to their antioxidative response. Generally, tolerant plant species can produce and maintain a larger amount of antioxidant molecules and an enhancement in antioxidant enzyme activity under stress conditions, so that they will have a better function to protect against saltinduced oxidative stress damage [78]. Typical land plant stress metabolites thus include many compounds with antioxidative potential such as phenols, flavonoids, and sinapate derivatives [79-81], but also enzymes involved in the detoxification of ROS [54-56,82].

While the lipid peroxidation level increases as a response to increasing $\mathrm{NaCl}$ concentrations in moss gametophyte cultures (Figure 8B), we could not detect a specific response in terms of an increase in total phenols as stress metabolites, rather their concentration decreased during $\mathrm{NaCl}$ stress (Figure $8 \mathrm{~A}$ ). Since flavonoids are present and play a role in early land plants such as M. polymorpha [48], the occurrence of flavonoids in P. patens during salt stress was assessed. The occurrence of quercetin derivatives has been reported in a thin layer chromatography analysis after UV treatment [37]. Recent work identified $P$. patens enzymes capable of converting naringenin to apigenin and a dihydrokaempferol 
derivative [49]. This indicates that enzymes capable of synthesizing flavonols are present, which might in vitro not reflect the complete in planta spectrum and that the color patterns we found could indeed correspond to the flavonols is mentioned in the results. After staining of P. patens cultures with DPBA, a decrease over time and higher $\mathrm{NaCl}$ stress for putative quercetin derivatives in yellow-orange were found, while the sinapate fraction (in blue) seemed to increase over time and stress level (Figure 7), but no changes between WT and mutant lines were observed (Figure S6). Other putative flavonoid derivatives as indicated by their typical fluorescence did not show any alterations. Of course, the precise identification of these compounds needs to be achieved in future work. Both groups of compounds are discussed as stress metabolites in plants, which are altered under different stress conditions [79-81]. In particular, the antioxidant function of flavonoids [80] could play a role in the stress response we observed in P. patens, since the lipid peroxidation levels were increased under $\mathrm{NaCl}$ stress (Figure $8 \mathrm{~B}$ ).

The activity of enzymes involved in the antioxidative stress response such as peroxidase and superoxide dismutase [82] was also analyzed. Interestingly, there is a report on the downregulation of peroxidases by several IAA amino acid conjugates [83]. Thus, a reduction of GH3 proteins that would also result in lower levels of IAA conjugates in P. patens could be involved in the mediation of the level of stress enzymes. However, there was no clear link towards an increase in total peroxidase activity between WT and mutants, since in all plant lines the activity increased at high $\mathrm{NaCl}$ levels (Figures 9a and S4). Therefore, the isoenzyme patterns were analyzed by native gel electrophoresis [54]. Here, an indication of a possible connection between $\mathrm{GH} 3$ double-KO lines and increased peroxidase activity was found (Figures $9 \mathrm{~b}$ and $\mathrm{S} 7$ ). In both tested mutant lines, there was an additional band visible, and one band also present in WT was considerably stronger in both mutant lines (marked by asterisks). Similarly, the isoenzyme patterns for superoxide dismutase were visualized after PAGE (Figures 10 and S7). While there were $\mathrm{NaCl}$-dependent changes in individual bands, only one mutant line showed a difference in WT, so it was concluded that this is most likely a line-specific effect, even though the targeted knock-out of the genes [15] in theory should not lead to such differences. The low response of SOD isoenzymes corresponds to the observation that $P$. patens double knock-out mutants for chloroplastic SOD does not show any alteration in abiotic stress tolerance, especially when the growth of protonema under high salt conditions was assayed [84].

This work has uncovered novel players in the salt stress response of $P$. patens independently of the auxin homeostasis. Browsing the available transcriptome $[9,10,41-44,66]$ and proteome sets [11] for P. patens can lead to many other putative targets by analyzing the genes upregulated by osmotic and salt stress, but the analysis of end products or enzyme activities helps to identify the active components of a stress response system more directly. For example, we have analyzed the most strongly co-expressed genes from Gene Atlas (Phytozome) [41,42] with the two PpGH3s as query and found some candidates involved in abiotic or biotic stress responses for PpGH3-1 (Table S2), among them two receptor protein tyrosine kinase/non-specific serine/threonine protein kinase/threonine-specific protein kinase; one WRKY DNA-binding domain). In addition, a gene encoding a TRYPTOPHAN SYNTHASE BETA CHAIN was strongly co-expressed with P $p G H 3-1$. The functional analysis of such targets identified by bioinformatic methods can further contribute to the salt stress response of P. patens.

\section{Materials and Methods}

\subsection{Plant Material and Experimental Conditions}

The plant material (WT and 4 GH3 double KO lines) was described in LudwigMüller et al. [15]. The moss cultivation was performed according to Mittag et al. [16] on Knop medium supplemented with $1.2 \%$ agar. Single gametophores were placed onto the plates (10 per plate) at the beginning of the experiment using forceps. Plates were sealed with micropore tape (3M, Neuss, Germany). Control plates did not contain any salt. Cultivation was performed in a growth chamber at $25 \pm 1{ }^{\circ} \mathrm{C}$ under a $16 / 8 \mathrm{~h}$ light/dark photoperiod. 
$\mathrm{NaCl}$ was added at the appropriate concentration $(50,100,250$, and $500 \mathrm{mM})$ to the agar plates. The respective IAA concentrations $(1$ and $10 \mu \mathrm{M})$ were added from stock solutions (IAA dissolved in ethanol, the final concentration was $1 \%$ in the agar plates after dilution) according to Ludwig-Müller et al. [15]. For revival experiments individual gametophores were removed from the $\mathrm{NaCl}$-containing agar and placed on Knop agar without salt. At different time points, as indicated in the results, plants were inspected, the diameter of the colonies measured at the widest point as described in Mittag et al. [16], and if appropriate for the respective analyses the plants were harvested to determine fresh weight as well as secondary metabolites, lipid peroxidation, hormones, and enzymes as described in more detail in the following sections. The growth rate was determined by subtracting the diameter of the respective moss colony at later time points from that of an earlier time point. In some cases, the values were normalized on the untreated samples and expressed as percent of control.

For the measurement of the fresh weight, the colonies were removed thoroughly from the plates to reduce contamination with agar. A comparison between the fresh and dry weight of each sample was done on day 36 for WT and two mutant lines (A129, B12) at zero and three salt concentrations. Of each sample a representative amount that was weighed before was kept in an oven at $65^{\circ} \mathrm{C}$ for 3 nights. After the samples were reduced to complete dryness, their dry weight was measured and the water loss calculated.

\subsection{Free IAA Determination}

The determination of free IAA was performed according to Ludwig-Müller et al. and Mittag et al. [15,16]. Briefly, the plant material was extracted with iso-propanol:acetic acid $(95: 5, v / v)$. To each sample $100 \mathrm{ng}{ }^{13} \mathrm{C}_{6}$-IAA (Cambridge Isotope Laboratories, Andover, MS, USA) was added. For each line three independent extractions were performed. Methylation of all samples was carried out with trimethylsilyldiazomethane [85]. GC-MS analysis was carried out on a Varian Saturn 2100 ion-trap mass spectrometer using electron impact ionization at $70 \mathrm{eV}$, connected to a Varian CP-3900 gas chromatograph equipped with a CP8400 autosampler (Varian, Walnut Creek, CA, USA). For the analysis $1 \mu \mathrm{L}$ of the methylated sample was injected onto a $30 \mathrm{~m}$ ZB-5 column (Phenomenex, Darmstadt, Germany) using $\mathrm{He}$ carrier gas at $1 \mathrm{~mL} \mathrm{~min}{ }^{-1}$. Injector temperature was $250{ }^{\circ} \mathrm{C}$ and the temperature program was $70^{\circ} \mathrm{C}$ for $1 \mathrm{~min}$, followed by an increase of $20^{\circ} \mathrm{C} \mathrm{min}-1$ to $280^{\circ} \mathrm{C}$, then $5 \mathrm{~min}$ isothermically at $280^{\circ} \mathrm{C}$. For higher sensitivity, the $\mu$ SIS mode was used. The settings of the MS were as previously described [86]. The endogenous concentrations of IAA were calculated according to the principles of isotope dilution [87] monitoring the quinolinium ions at $\mathrm{m} / \mathrm{z}$ 130/136 (ions deriving from endogenous and ${ }^{13} \mathrm{C}_{6}$-IAA, respectively).

\subsection{Lipid Peroxidation Determination}

The determination of the lipid peroxidation level was done by determination of a product of lipid peroxidation, malondialdehyde (MDA), content using the thiobarbituric acid (TBA) reaction according to Heath and Packer [88] with minor modifications. The MDA content was measured after 12, 24, and 36 days after transfer to salt-containing or control plates. From each sample $120 \mathrm{mg}$ fresh weight was homogenized in $1 \mathrm{~mL}$ extraction solution, consisting of $0.1 \%$ trichloroacetic (TCA) and $1 \%$ sodium dodecyl sulfate (SDS) in distilled water. Homogenization was done in a cold mortar and with a pestle, using liquid $\mathrm{N}_{2}$. The homogenate was centrifuged at $4{ }^{\circ} \mathrm{C}$ at $15,000 \times g$ for $15 \mathrm{~min}$. Of the supernatant $300 \mu \mathrm{L}$ was added to $1 \mathrm{~mL}$ of the MDA reagent, including $20 \%$ TCA-SDS solution and $0.5 \%$ TBA. The mixture was incubated at $95^{\circ} \mathrm{C}$ for $30 \mathrm{~min}$ and then cooled on ice. After centrifugation at $4{ }^{\circ} \mathrm{C}$ for $10 \mathrm{~min}$, the absorbance of the supernatant was measured at $532 \mathrm{~nm}$. The concentration of MDA was calculated using its extinction coefficient $(\varepsilon \mathrm{M})$ of $155 \mathrm{mM}^{-1} \mathrm{~cm}^{-1}$. Each sample was repeated three times and finally the mean was expressed in nanomoles malondialdehyde per gram fresh weight (nmol MDA/g FW). 


\subsection{Total Phenol Determination}

The total phenolic content of samples was determined 12, 24, and 36 days after transfer to $\mathrm{NaCl}$ or control plans of the same age using the Folin-Ciocalteu (FC) method [89]. From each sample $100 \mathrm{mg}$ fresh weight was homogenized in $2 \mathrm{~mL} 70 \% \mathrm{MeOH}$ using mortar and pestle. The homogenates were kept at room temperature for 5-10 min under gentle shaking and were then centrifuged for $5 \mathrm{~min}$ at $1500 \times g$. The supernatants were evaporated to the aqueous phase under a stream of nitrogen and the $\mathrm{pH}$ was adjusted to 3 . Total phenols were extracted using two volumes of ethyl acetate and the samples were centrifuged at $1500 \times g$. The procedure was repeated twice. The organic phases were carefully removed and collected after each centrifugation step and combined. The collected supernatants were evaporated to dryness under $\mathrm{N}_{2}$ and dissolved in $100 \mu \mathrm{L}$ methanol. The total volume of the samples (plant and standards) was mixed with $500 \mu \mathrm{L}$ FC reagent and $400 \mu \mathrm{L} \mathrm{Na}_{2} \mathrm{CO}_{3}$ and incubated for $2 \mathrm{~h}$ at room temperature in the darkness. The absorbance of triplicate samples was measured at $765 \mathrm{~nm}$. To calculate the total phenolic content a standard curve of known concentrations of gallic acid (GA) was measured. For this, a $25 \mathrm{mg} \mathrm{mL}^{-1}$ stock solution of GA was made up by dissolving the respective concentration of GA $(25,50,100$, 150 , and $200 \mathrm{mg} / \mathrm{L}$ ) in methanol (95\%). Each sample was repeated three times and the mean was expressed in $\mathrm{mg} \mathrm{GA} \mathrm{g} \mathrm{FW}{ }^{-1}$.

\subsection{In Situ Staining of Flavonoids}

The fluorescence of diphenylboric acid 2-amino-ethyl-ester (DPBA) conjugated to the flavonoid compounds, after excitation with blue light, was used to visualize the locations of the flavonoid compounds in situ according to Buer and Muday [50]. The staining was carried out using individual plants 12, 24, and 36 days after transfer to control and salt-containing plates. A 10\% (w/v) stock solution of DPBA in $95 \% \mathrm{MeOH}$ was prepared, which was diluted to $0.25 \%$ DPBA in distilled $\mathrm{H}_{2} \mathrm{O}$ containing $0.005 \%(v / v)$ Triton X-100. All samples were incubated for $15 \mathrm{~min}$ and then washed for $5 \mathrm{~min}$ in $100 \mathrm{mM}$ sodium phosphate buffer, $\mathrm{pH} 7$ (including $0.005 \%(v / v)$ Triton X-100, 0). Negative controls without DPBA reagent were prepared to confirm that the fluorescence colors came from the DPBA conjugates. After staining, the samples were placed on slides using 50\% $(v / v)$ glycerol. Fluorescence was visualized by excitation with blue radiation and the following filter (G365/FT395/LP420) on a Zeiss Axioskop 2 (Carl Zeiss, Jena, Germany) fluorescence microscope (at $366 \mathrm{~nm}$ the fluorescences of quercetin were yellow, of kaempferol green and of naringenin cyan).

\subsection{Protein Extraction}

The plant samples were prepared 12, 24, and 36 days after transfer to control and salt-containing plates according to a modified method of Qureshi et al. [90]. Ca $120 \mathrm{mg}$ fresh weight of the respective plant material was homogenized in a cold mortar with a pestle and $350 \mu \mathrm{L}$ cold extraction buffer of $100 \mathrm{mM}$ potassium-phosphate buffer, $\mathrm{pH}$ 7.4, containing $1 \mathrm{mM}$ ethylenediaminetetraacetic acid and $1 \mathrm{mM}$ phenylmethylsulfonyl fluoride. After centrifugation at $15,000 \times \mathrm{g}$ and $4{ }^{\circ} \mathrm{C}$ for $25 \mathrm{~min}$, the total protein content of the supernatants was spectrophotometrically measured (see below) and the extracts were used for the enzyme assays described below.

\subsection{Total Protein Determination}

Total protein content was measured using the bicinchoninic acid (BCA) method according to the manufacturer's instructions. The plant material was extracted with the respective buffers used for enzyme determination. When reducing agents were present, the proteins were precipitated with acetone ( $400 \mu \mathrm{L}$ added to $200 \mu \mathrm{L}$ protein solution, $30 \mathrm{~min}$ incubation at $-20^{\circ} \mathrm{C}$, centrifugation for $5 \mathrm{~min}$ at $15,000 \times g$ ) from the buffer solution. The preparation and assaying were according to the instructions for the BCA Protein Assay Reagent Kit (Thermo Fisher Scientific, Dreieich, Germany). The absorbance was measured at $562 \mathrm{~nm}$. Different dilutions of Bovine Serum Albumin Standard (BSA) in the extraction 
buffer with the working range of $5-250 \mu \mathrm{g} / \mathrm{mL}$ were used to create a standard curve. All samples were measured in triplicates.

\subsection{Peroxidase Enzyme Activity}

In order to determine peroxidase activity, o-phenylenediamine (OPD) was used as substrate [54]. A protein extract $(5 \mu \mathrm{g})$ was incubated for $15 \mathrm{~min}$ with $0.5 \mathrm{~mL}$ substrate buffer (one tablet of OPD in $5 \mathrm{~mL} 20 \mathrm{mM}$ Tricine- $\mathrm{KOH}$, pH 7.0, containing 3.6\% $\mathrm{H}_{2} \mathrm{O}_{2}$ ). The substrate buffer should be freshly prepared and the tablets have to be dissolved fresh on the day of the experiment. After the incubation time, $0.5 \mathrm{~mL} 0.5 \mathrm{M} \mathrm{H}_{2} \mathrm{SO}_{4}$ was used to stop the reaction. The absorbance of the samples was determined at $490 \mathrm{~nm}$. In order to calculate the enzyme activity, a defined amount of horseradish peroxidase was used for the preparation of the standard curve. For this aim, different dilutions of horseradish peroxidase in extraction buffer with the working range of $0.1-10 \mathrm{mU} \mu \mathrm{L}^{-1}$ were prepared. A standard curve was plotted based on their absorbance at $490 \mathrm{~nm}$.

\subsection{Native Polyacrylamide Gel Electrophoresis (PAGE)}

The detection of the isoenzyme patterns for two different groups of enzymes was performed on a native poly-acrylamide gel electrophoresis in the presence of low amounts of SDS $(0.1 \%)$ in the running buffer. No reducing agents were present [54]. For the detection of the enzyme activities, the electrophoresis was carried out at $4{ }^{\circ} \mathrm{C}$. Total proteins were separated and the resulting patterns were stained for peroxidase (POX) and superoxide dismutase (SOD) activities and total protein (Coomassie). Equal amounts of protein $(50 \mu \mathrm{g})$ were loaded in each lane of the gels. The resolving gel and stacking gel had acrylamide concentrations of $10 \%$ and $5 \%$, respectively. A molecular mass marker (Thermo Fisher Scientific, Dreieich, Germany) was run on all gels along with the tested samples.

\subsubsection{Peroxidase Isoenzyme Detection}

The detection of the peroxidase isoenzyme patterns was performed according to Ludwig-Müller et al. [54] using benzidine-guaiacol as substrates to visualize the bands. The staining solution comprised of solution A: $40 \mathrm{~mL} 0.2 \mathrm{M} \mathrm{Na}$-acetate, $4 \mathrm{~mL} 5 \mathrm{mM} \mathrm{MnSO}_{4}$, $4 \mathrm{~mL} 0.35 \% \mathrm{H}_{2} \mathrm{O}_{2}$ and solution B: $20 \mathrm{mg}$ benzidine (4,4'-diaminobiphenyl), $10 \mathrm{~mL} \mathrm{10 \%}$ acetic acid, $54 \mu \mathrm{L}$ guaiacol. When the run of the polyacrylamide gel was completed, the gel was quickly rinsed in $\mathrm{H}_{2} \mathrm{O}$ and then placed into solution $\mathrm{A}$. Incubation was performed at room temperature. Under constant shaking, solution B was added to the gel. Staining was continued until the POX bands were visible on the gel. The reaction was stopped by replacing the staining solution several times with water. The density of the bands was detected and displayed using the GelEval software free trial version 1.35 (FrogDanceSoftware, Cambridge, UK).

\subsubsection{Superoxide Dismutase Isoenzyme Detection}

SOD isoenzymes were detected in the gels by their ability to inhibit the photochemical reduction of nitroblue tetrazolium (NBT). The staining of the gels was performed based on the method described by Pitzschke et al. [55] with some modifications. The gels were rinsed in cold distilled water, then incubated for 20-25 min in $2 \mathrm{mM} \mathrm{NBT}$ (made in $100 \mathrm{mM}$ potassium phosphate buffer, $\mathrm{pH} 7.8$ ) under constant agitation in light at $4{ }^{\circ} \mathrm{C}$. The NBT solution was then replaced with riboflavin solution [45] $(0.030 \mathrm{mM}$ riboflavin, $1 \% \mathrm{~N}, \mathrm{~N}$, $\mathrm{N}^{\prime}, \mathrm{N}^{\prime}$-tetramethylethylenediamine (TEMED) in the same buffer) and the gels were further incubated for 25-30 min at $4{ }^{\circ} \mathrm{C}$ in darkness. Finally, the gels were briefly rinsed in distilled water and SOD activity was shown by white bands against a violet background.

\subsubsection{Total Protein Staining with Colloidal Commassie}

The total protein pattern was determined using the colloidal Coomassie staining method based on the protocol of Neuhoff et al. [91] with some modifications. The gel was incubated for $20 \mathrm{~min}$ in $50 \mathrm{~mL}$ solution A (10\% (w/v) ammonium sulfate, $2 \%$ phosphoric acid 
in distilled $\mathrm{H}_{2} \mathrm{O}$ ) containing $1.25 \mathrm{~mL}$ solution $\mathrm{B}(5 \%(w / v)$ Coomassie Brilliant Blue G250 in distilled $\mathrm{H}_{2} \mathrm{O}$ ) under continuous shaking. The gel was then destained in $25 \%$ methanol in distilled $\mathrm{H}_{2} \mathrm{O}$ followed by destaining in methanol until the background was clear.

\subsection{Statistical Analysis}

The results of the experiments were analyzed using the "IBM SPSS Statistics 20" program. Data are the mean values of at least three replicates. The error bars shown in all bar graphs represent standard deviation calculated from all repetitions of each experiment. Analysis of independent data was done by the two-way ANOVA (univariate) method and the significance of differences was determined using the Tukey test. The test of a Repeated Measurement ANOVA was carried out in order to analyze the dependent data [92,93]. Differences at the level of $p \leq 0.05$ were considered significant.

\subsection{Digital Expression and Promoter Element Analyses}

Digital transcription analysis with the annotated gene numbers for PpGH3.1 (Pp3c24_ 16260V3.1/Pp1s323_82V6.1) and PpGH3-2 (Pp3c10_20960V3.1/Pp1s67_243V6.1), the numbers depend on the annotation version, as a query was used to analyze the transcription levels under various stress conditions using available web resources (Phytozome, GeneAtlas) [41-44]. The promoter sequences of both GH3 genes (circa $3 \mathrm{~kb}$ upstream of the transcription start in the genome sequence) was analyzed for the occurrence of possible regulatory elements taken from Phytozome [41]).

\section{Conclusions}

In conclusion, our results show that selected parameters connected to oxidative stress are differentially regulated in $P$. patens after exposing gametophore tissue to high salt concentrations $(250 \mathrm{mM})$, but that these was not dependent upon the auxin conjugating $\mathrm{GH} 3$ proteins. However, the auxin conjugate formation catalyzed by the GH3 proteins seems to be involved in stress response regulation since two of the double $\mathrm{KO}$ mutants were more resistant to high salt concentrations. The results indicate the delicate balance between growth and stress adaptation through the regulation of free auxin levels since the double $\mathrm{KO}$ mutant lines showed a growth inhibition under normal conditions and at high auxin levels but grew better in high salt conditions. However, the high auxin levels in the mutant lines presumably did not confer the induction of other stress responses.

Supplementary Materials: The following are available online at https: / www.mdpi.com/article/ 10.3390/plants10071398/s1, Figure S1: Wild type and 4 independent GH3 double-KO mutants of P. patens under control and at different salt concentrations over time. Figure S2: Fresh weight and growth rate for wild type and 4 independent GH3 double-KO mutants of $P$. patens. Figure S3: Fresh weight and dry weight to calculate the water loss in the tissue for wild type and 2 independent GH3 double-KO mutants of $P$. patens. Figure S4: Total protein content, lipid peroxidation, total phenol content, and peroxidase activity in wild type and 4 independent GH3 double-KO mutants of P. patens. Figure S5: KEGG pathway for flavonoids in P. patens. Figure S6: In situ flavonoid staining in wild type and 4 independent GH3 double-KO mutants of P. patens. Figure S7: The original PAGE gels for total protein stained with colloidal Coomassie blue (A), peroxidase isoenzyme separation (B) and superoxide dismutate (SOD) isoenzyme separation (C) for wild type and four independent GH3 double-KO mutants of $P$. patens. Table S1: Analysis of stress and stress hormone related elements in the promoter of the two P. patens GH3 genes. Table S2: The most strongly co-expressed genes for PpGH3-1 and PpGH3-2.

Author Contributions: Conceptualization, J.L.-M.; methodology, H.K., formal analysis, H.K. and J.L.-M.; investigation, H.K., resources, J.L.-M.; writing—original draft preparation, J.L.-M.; writingreview and editing, J.L.-M. and H.K., visualization, H.K. and J.L.-M.; supervision, J.L.-M.; project administration, J.L.-M. All authors have read and agreed to the published version of the manuscript.

Funding: This research received no external funding.

Institutional Review Board Statement: Not applicable. 
Informed Consent Statement: Not applicable.

Data Availability Statement: All data supporting this study are available in this paper and in its supplementary data published online.

Acknowledgments: We would like to thank the TU Dresden Gesellschaft der Freunde und Förderer and the Graduate Academy for stipends to H.K. We also acknowledge the technical assistance of Sabine Rößler, TU Dresden.

Conflicts of Interest: The authors declare no conflict of interest.

\section{References}

1. Iqbal, N.; Umar, S.; Khan, N.A. Nitrogen availability regulates proline and ethylene production and alleviates salinity stress in mustard (Brassica juncea). J. Plant Physiol. 2015, 178, 84-91. [CrossRef]

2. Zhang, X.; Lu, G.; Long, W.; Zou, Y.; Li, F.; Nishio, T. Recent progress in drought and salt tolerance studies in Brassica crops. Breed. Sci. 2014, 64, 60-73. [CrossRef] [PubMed]

3. Rensing, S.A.; Goffinet, B.; Meyberg, R.; Wu, S.-Z.; Bezanilla, M. The moss Physcomitrium (Physcomitrella) patens: A model organism for non-seed plants. Plant Cell 2020. [CrossRef]

4. Frank, W.; Ratnadewi, D.; Reski, R. Physcomitrella patens is highly tolerant against drought, salt and osmotic stress. Planta 2005, 220, 384-394. [CrossRef]

5. Arif, M.A.; Alseekh, S.; Harb, J.; Fernie, A.; Frank, W. Abscisic acid, cold and salt stimulate conserved metabolic regulation in the moss Physcomitrella patens. Plant Biol. 2018, 20, 1014-1022. [CrossRef] [PubMed]

6. Ruibal, C.; Castro, A.; Carballo, V.; Szabados, L.; Vidal, S. Recovery from heat, salt and osmotic stress in Physcomitrella patens requires a functional small heat shock protein PpHsp16.4. BMC Plant Biol. 2013, 13, 174. [CrossRef] [PubMed]

7. Mittag, J.; Šola, I.; Rusak, G.; Ludwig-Müller, J. Physcomitrella patens auxin conjugate synthetase (GH3) double knockout mutants are more resistant to Pythium infection than wild type. J. Plant Physiol. 2015, 183, 75-83. [CrossRef]

8. Ponce de León, I.; Oliver, J.; Castro, A.; Gaggero, C.; Bentancor, M.; Vidal, S. Erwinia carotovora elicitors and Botrytis cinerea activate defense responses in Physcomitrella patens. BMC Plant Biol. 2007, 7, 52. [CrossRef]

9. Richardt, S.; Timmerhaus, G.; Lang, D.; Qudeimat, E.; Corrêa, L.G.G.; Reski, R.; Rensing, S.A.; Frank, W. Microarray analysis of the moss Physcomitrella patens reveals evolutionarily conserved transcriptional regulation of salt stress and abscisic acid signalling. Plant Mol. Biol. 2010, 72, 27-45. [CrossRef]

10. Beike, A.K.; Lang, D.; Zimmer, A.D.; Wüst, F.; Trautmann, D.; Wiedemann, G.; Beyer, P.; Decker, E.L.; Reski, R. Insights from the cold transcriptome of Physcomitrella patens: Global specialization pattern of conserved transcriptional regulators and identification of orphan genes involved in cold acclimation. New Phytol. 2015, 205, 869-881. [CrossRef]

11. Wang, X.; Liu, Y.; Yang, P. Proteomic studies of the abiotic stresses response in model moss—Physcomitrella patens. Front. Plant Sci. 2012, 3, 1-8. [CrossRef]

12. Saavedra, L.; Svensson, J.; Carballo, V.; Izmendi, D.; Welin, B.; Vidal, S. A dehydrin gene in Physcomitrella patens is required for salt and osmotic stress tolerance. Plant J. 2006, 45, 237-249. [CrossRef]

13. Bogdanović, M.; Ilić, M.; Živković, S.; Sabovljević, A.; Grubišić, D.; Sabovljević, M. Comparative study on the effects of NaCl on selected moss and fern representatives. Aust. J. Bot. 2011, 59, 734-740. [CrossRef]

14. Ludwig-Müller, J. Auxin conjugates: Their role for plant development and in the evolution of land plants. J. Exp. Bot. 2011, 62, 1757-1773. [CrossRef]

15. Ludwig-Müller, J.; Jülke, S.; Bierfreund, N.M.; Decker, E.L.; Reski, R. Moss (Physcomitrella patens) GH3 proteins act in auxin homeostasis. New Phytol. 2008, 181, 323-338. [CrossRef]

16. Mittag, J.; Gabrielyan, A.; Ludwig-Müller, J. Knockout of GH3 genes in the moss Physcomitrella patens leads to increased IAA levels at elevated temperature and in darkness. Plant Physiol. Biochem. 2015, 97, 339-349. [CrossRef]

17. Junghans, U.; Polle, A.; Düchting, P.; Weiler, E.; Kuhlmann, B.; Gruber, F.; Teichmann, T. Adaptation to high salinity in poplar involves changes in xylem anatomy and auxin physiology. Plant Cell Environ. 2006, 29, 1519-1531. [CrossRef] [PubMed]

18. Salopek-Sondi, B.; Samec, D.; Mihaljević, S.; Smolko, A.; Pavlović, I.; Janković, I.; Ludwig-Müller, J. Influence of stress hormones on the auxin homeostasis in Brassica rapa seedlings. Plant Cell Rep. 2013, 32, 1031-1042. [CrossRef] [PubMed]

19. Ksouri, R.; Megdiche, W.; Debez, A.; Falleh, H.; Grignon, C.; Abdelly, C. Salinity effects on polyphenolcontent and antioxidant activities in leaves of the halophyte Cakile maritima. Plant Physiol. Biochem. 2007, 45, 244-249. [CrossRef] [PubMed]

20. Sztein, A.E.; Cohen, J.D.; Slovin, J.P.; Cooke, T.J. Auxin metabolism in representative land plants. Am. J. Bot. 1995, 82, 1514-1521. [CrossRef]

21. Sztein, A.E.; Cohen, J.D.; Garcia de la Fuente, I.; Cooke, T.J. Auxin metabolism in mosses and liverworts. Am. J. Bot. 1999, 86, 1544-1555. [CrossRef]

22. Campanella, J.; Kurdach, S.; Skibitski, R.; Smalley, J.; Desind, S.; Ludwig-Müller, J. Evidence for the early evolutionary loss of the M20D auxin amidohydrolase family from mosses and horizontal gene transfer from soil bacteria of cryptic hydrolase orthologues to Physcomitrella patens. J. Plant Growth Regul. 2019, 38, 1428-1438. [CrossRef] 
23. Zhang, C.; Zhang, L.; Wang, D.; Ma, H.; Liu, B.; Shi, Z.; Ma, X.; Chen, Y.; Chen, Q. Evolutionary history of the glycoside hydrolase 3 (GH3) family based on the sequenced genomes of 48 plants and identification of jasmonic acid-related GH3 proteins in Solanum tuberosum. Int. J. Mol. Sci. 2018, 19, 1850. [CrossRef]

24. Campanella, J.J.; Kurdach, S.; Bochis, J.; Smalley, J.V. Evidence for exaptation of the Marchantia polymorpha M20D peptidase MpILR1 into the tracheophyte auxin regulatory pathway. Plant Physiol. 2018, 177, 1595-1604. [CrossRef]

25. Drábková, L.Z.; Dobrev, P.I.; Motyka, V. Phytohormone profiling across the bryophytes. PLoS ONE 2015, 10, e0125411. [CrossRef]

26. Landberg, K.; Simura, J.; Ljung, K.; Sundberg, E.; Thelander, M. Studies of moss reproductive development indicate that auxin biosynthesis in apical stem cells may constitute an ancestral function for focal growth control. New Phytol. 2021, 229, 845-860. [CrossRef]

27. Thelander, M.; Landberg, K.; Sundberg, E. Auxin-mediated developmental control in the moss Physcomitrella patens. J. Exp. Bot. 2018, 69, 277-290. [CrossRef] [PubMed]

28. Rose, S.; Rubery, P.H.; Bopp, M. The mechanism of auxin uptake and accumulation in moss protonemata. Physiol. Plant. 1983, 58, 52-56. [CrossRef]

29. Viaene, T.; Landberg, K.; Thelander, M.; Medvecka, E.; Pederson, E.; Feraru, E.; Cooper, E.D.; Karimi, M.; Delwiche, C.F.; Ljung, K.; et al. Directional auxin transport mechanisms in early diverging land plants. Current Biol. 2014, 24, 2786-2791. [CrossRef] [PubMed]

30. Mohanta, T.K.; Mohanta, N. Genome wide identification of auxin efflux carrier gene family in Physcomitrella patens. J. Biotechnol. Sci. 2013, 1, 54-64. Available online: http:/ / drabbas.org/jbs / (accessed on 7 July 2021).

31. Porco, S.; Pěnčík, A.; Rashed, A.; Voß, U.; Casanova-Sáez, R.; Bishopp, A.; Golebiowska, A.; Bhosale, R.; Swarup, R.; Swarup, K.; et al. Dioxygenase-encoding AtDAO1 gene controls IAA oxidation and homeostasis in Arabidopsis. Proc. Natl. Acad. Sci. USA 2016, 113, 11016-11021. [CrossRef]

32. Zhang, J.; Lin, J.E.; Harris, C.; Campos Mastrotti Pereira, F.; Wu, F.; Blakeslee, J.J.; Peer, W.A. DAO1 catalyzes temporal and tissue-specific oxidative inactivation of auxin in Arabidopsis thaliana. Proc. Natl. Acad. Sci. USA 2016, 113, 11010-11015. [CrossRef] [PubMed]

33. Keilig, K.; Ludwig-Müller, J. Effect of Flavonoids on Heavy Metal Tolerance in Arabidopsis thaliana Seedlings. Botan. Stud. 2009, 50,311-318. Available online: http:/ / ejournal.sinica.edu.tw/bbas/content/2009/3/Bot503-05.pdf (accessed on 7 July 2021).

34. Emiliani, J.; Grotewold, E.; Ferreyra, M.L.F.; Casati, P. Flavonols protect arabidopsis plants against UV-B deleterious effects. Mol. Plant 2013, 6, 1376-1379. [CrossRef]

35. Abogadallah, G.M. Antioxidative defense under salt stress. Plant Signal. Behav. 2010, 5, 369-374. [CrossRef] [PubMed]

36. Pollastri, S.; Tattini, M. Flavonols: Old compounds for old roles. Ann. Bot. 2011, 108, 1225-1233. [CrossRef]

37. Wolf, L.; Rizzini, L.; Stracke, R.; Ulm, R.; Rensing, S.A. The molecular and physiological responses of Physcomitrella patens to Ultraviolet-B radiation. Plant Physiol. 2010, 153, 1123-1134. [CrossRef] [PubMed]

38. Pinhero, R.G.; Rao, M.V.; Paliyath, C.; Murr, D.P.; Fletcher, R.A. Changes in activities of antioxidant enzymes and their relationship to genetic and paclobutrazol induced chilling tolerance of maize seedlings. Plant Physiol. 1997, 114, 695-704. [CrossRef]

39. Lunde, C.; Drew, D.P.; Jacobs, A.K.; Tester, M. Exclusion of $\mathrm{Na}^{+}$via Sodium ATPase (PpENA1) ensures normal growth of Physcomitrella patens under moderate salt stress. Plant Physiol. 2007, 144, 1786-1796. [CrossRef] [PubMed]

40. JGI Phytozome 12-The Plant Genomic Resource. Available online: https://phytozome.jgi.doe.gov/pz/portal.html\#!gene? search $=1$ \&detail=1\&method=5013\&searchText=transcriptid:32910187 (accessed on 13 August 2019).

41. Perroud, P.; Haas, F.B.; Hiss, M.; Ullrich, K.K.; Alboresi, A.; Amirebrahimi, M.; Barry, K.; Bassi, R.; Bonhomme, S.; Chen, H.; et al. The Physcomitrella patens gene atlas project: Large-scale RNA-seq based expression data. Plant J. 2018, 95, 168-182. [CrossRef] [PubMed]

42. BAR-The Bio-Analytic Resource for Plant Biology. Available online: http://bar.utoronto.ca/efp_physcomitrella/cgi-bin/ efpWeb.cgi (accessed on 13 August 2019).

43. Ortiz-Ramírez, C.; Hernandez-Coronado, M.; Thamm, A.; Catarino, B.; Wang, M.; Dolan, L.; Feijó, J.A.A.; Becker, J.D. A Transcriptome Atlas of Physcomitrella patens provides insights into the evolution and development of land plants. Mol. Plant 2016, 9, 205-220. [CrossRef]

44. Oldenhof, H.; Wolkers, W.F.; Bowman, J.L.; Tablin, F.; Crowe, J.H. Freezing and desiccation tolerance in the moss Physcomitrella patens: An in situ Fourier transform infrared spectroscopic study. Biochim. Biophys. Acta 2006, 1760, 1226-1234. [CrossRef]

45. Koster, K.L.; Balsamo, R.A.; Espinoza, C.; Oliver, M.J. Desiccation sensitivity and tolerance in the moss Physcomitrella patens: Assessing limits and damage. Plant Growth Regul. 2010, 62, 293-302. [CrossRef]

46. Cuming, A.C.; Cho, S.H.; Kamisugi, Y.; Graham, H.; Quatrano, R.S. Microarray analysis of transcriptional responses to abscisic acid and osmotic, salt, and drought stress in the moss, Physcomitrella patens. New Phytol. 2007, 176, 275-287. [CrossRef]

47. Peer, W.A.; Murphy, A.S. Flavonoids and auxin transport: Modulators or regulators? Trends Plant Sci. 2007, 12, 556-563. [CrossRef]

48. Yonekura-Sakakibara, K.; Higashi, Y.; Nakabayashi, R. The origin and evolution of plant flavonoid metabolism. Front. Plant Sci. 2019, 10, 943. [CrossRef]

49. Li, D.-D.; Ni, R.; Wang, P.-P.; Zhang, X.-S.; Wang, P.-Y.; Zhu, T.-T.; Sun, C.-J.; Liu, C.-J.; Lou, H.-X.; Cheng, A.-X. Molecular basis for chemical evolution of flavones to flavonols and anthocyanins in land plants. Plant Physiol. 2020. [CrossRef] [PubMed]

50. Buer, C.S.; Imin, N.; Djordjevic, M.A. Flavonoids: New roles for old molecules. J. Integr. Plant Biol. 2010, 52, 98-111. [CrossRef] [PubMed] 
51. Stracke, R.; Jahns, O.; Keck, M.; Tohge, T.; Niehaus, K.; Fernie, A.R.; Weisshaar, B. Analysis of PRODUCTION OF FLAVONOL GLYCOSIDES-dependent flavonol glycoside accumulation in Arabidopsis thaliana plants reveals MYB11-, MYB12- and MYB111independent flavonol glycoside accumulation. New Phytol. 2010, 188, 985-1000. [CrossRef] [PubMed]

52. Rusak, G.; Cerni, S.; Stupin Polancec, D.; Ludwig-Müller, J. The Responsiveness of the IAA2 Promoter to IAA and IBA is Differentially Affected in Arabidopsis Roots and Shoots by Flavonoids. Biol. Plant. 2010, 54, 403-414. [CrossRef]

53. Buer, C.S.; Muday, G.K. The transparent testa 4 mutation prevents flavonoid synthesis and alters auxin transport and the response of Arabidopsis roots to gravity and light. Plant Cell 2004, 16, 1191-1205. [CrossRef]

54. Ludwig-Müller, J.; Thermann, P.; Pieper, K.; Hilgenberg, W. Peroxidase and chitinase isoenzyme activiti.es during root infection of Chinese cabbage with Plasmodiophora brassicae. Physiol. Plant. 1994, 90, 661-670. [CrossRef]

55. Pitzschke, A.; Fraundorfer, A.; Guggemos, M.; Fuchs, N. Antioxidative responses during germination in quinoa grown in Vitamin B-rich medium. Food Sci. Nutr. 2015, 3, 242-251. [CrossRef]

56. Bertrand, R.L.; Eze, M.O. Modifying polyacrylamide background color for the nitroblue tetrazolium-based superoxide dismutase staining assay. Adv. Enz. Res. 2014, 2, 77-81. [CrossRef]

57. Staswick, P.E.; Serban, B.; Rowe, M.; Tiryaki, I.; Maldonado, M.T.; Maldonado, M.C.; Suza, W. Characterization of an Arabidopsis enzyme family that conjugates amino acids to indole-3-acetic acid. Plant Cell 2005, 17, 616-627. [CrossRef]

58. Liang, W.; Ma, X.; Wan, P.; Liu, L. Plant salt-tolerance mechanism: A review. Biochem. Biophys. Res. Commun. 2018, 495, $286-291$. [CrossRef] [PubMed]

59. Albacete, A.; Ghanem, M.E.; Martinez-Andujar, C.; Acosta, M.; Sanchez-Bravo, J.; Martinez, V.; Lutts, S.; Dodd, I.C.; Pérez-Alfocea, F. Hormonal changes in relation to biomass partitioning and shoot growth impairment in salinized tomato (Solanum lycopersicum L.) plants. J. Exp. Bot. 2008, 59, 4119-4131. [CrossRef] [PubMed]

60. Prakash, L.; Prathapasenan, G. NaCl-and gibberellic acid-induced changes in the content of auxin and the activities of cellulase and pectin lyase during leaf growth in rice (Oryza sativa). Ann. Bot. 1990, 65, 251-257. [CrossRef]

61. Shakirova, F.M.; Sakhabutdinova, A.R.; Bezrukova, M.V.; Fatkhutdinova, R.A.; Fatkhutdinova, D.R. Changes in the hormonal status of wheat seedlings induced by salicylic acid and salinity. Plant Sci. 2003, 164, 317-322. [CrossRef]

62. Popko, J.; Hänsch, R.; Mendel, R.R.; Polle, A.; Teichmann, T. The role of abscisic acid and auxin in the response of poplar to abiotic stress. Plant Biol. 2010, 12, 242-258. [CrossRef] [PubMed]

63. Pavlović, I.; Pěnčík, A.; Novák, O.; Vujcic, V.; Brkanac, S.R.; Lepedus, H.; Strnad, M.; Salopek-Sondi, B. Short-term salt stress in Brassica rapa seedlings causes alterations in auxin metabolism. Plant Physiol. Biochem. 2018, 125, 74-84. [CrossRef]

64. Teichmann, T.; Bolu-Arianto, W.H.; Olbrich, A.; Langenfeld-Heyser, R.; Göbel, C.; Grzeganek, P.; Feussner, I.; Hänsch, R.; Polle, A. GH3::GUS reflects cell-specific developmental patterns and stress-induced changes in wood anatomy in the poplar stem. Tree Physiol. 2008, 28, 1305-1315. [CrossRef] [PubMed]

65. Schaefer, D.G.; Zrÿd, J.-P. The moss Physcomitrella patens, now and then. Plant Physiol. 2001, 127, 1430-1438. [CrossRef] [PubMed]

66. Khandelwal, A.; Cho, S.H.; Marella, H.; Sakata, Y.; Perroud, P.F.; Pan, A.; Quatrano, R.S. Role of ABA and ABI3 in desiccation tolerance. Science 2010, 327, 546. [CrossRef] [PubMed]

67. Decker, E.L.; Frank, W.; Sarnighausen, E.; Reski, R. Moss systems biology en route: Phytohormones in Physcomitrella development. Plant Biol. 2006, 8, 397-406. [CrossRef]

68. Cove, D.; Bezanilla, M.; Harries, P.; Quatrano, R. Mosses as model systems for the study of metabolism and development. Annu. Rev. Plant. Biol. 2006, 57, 497-520. [CrossRef] [PubMed]

69. Prigge, M.J.; Lavy, M.; Ashton, N.W.; Estelle, M. Physcomitrella patens auxin-resistant mutants affect conserved elements of an auxin-signaling pathway. Curr. Biol. 2010, 20, 1907-1912. [CrossRef]

70. Thelander, M.; Olsson, T.; Ronne, H. Effect of the energy supply on filamentous growth and development in Physcomitrella patens. J. Exp. Bot. 2005, 412, 653-662. [CrossRef]

71. Glime, J.M. Ecophysiology of Development: Protonemata. In Bryophyte Ecology (Digital Commons@Michigan Tech); Glime, J.M., Ed.; Physiological Ecology, 2013; Volume 1, Chapter 5-3; pp. 1-18. Available online: www.bryoecol.mtu.edu (accessed on 14 January 2021).

72. Jang, G.; Dolan, L. Auxin promotes the transition from chloronema to caulonema in moss protonema by positively regulating PpRSL1 and PpRSL2 in Physcomitrella patens. New Phytol. 2011, 192, 319-327. [CrossRef]

73. Tognetti, V.B.; Van Aken, O.; Morreel, K.; Vandenbroucke, K.; van de Cotte, B.; De Clercq, I.; Chiwocha, S.; Fenske, R.; Prinsen, E.; Boerjan, W.; et al. Perturbation of indole-3-butyric acid homeostasis by the UDP-Glucosyltransferase UGT74E2 modulates Arabidopsis architecture and water stress tolerance. Plant Cell 2010, 22, 2660-2679. [CrossRef]

74. Dunlap, J.R.; Binzel, M.L. NaCl reduces indole-3-acetic acid levels in the roots of tomato plants independent of stress-induced abscisic acid. Plant Physiol. 1996, 112, 379-384. [CrossRef]

75. Ludwig-Müller, J.; Decker, E.L.; Reski, R. Dead end for auxin conjugates in Physcomitrella? Plant Signal. Behav. 2009, 4, 116-118. [CrossRef]

76. Smolko, A.; Ludwig-Müller, J.; Salopek-Sondi, B. Auxin amidohydrolases-From structure to function: Revisited. Croat. Chem. Acta 2018, 91, 233-239. [CrossRef]

77. Reginato, M.A.; Castagna, A.; Furlán, A.; Castro, S.; Ranieri, A.; Luna, V. Physiological responses of a halophytic shrub to salt stress by $\mathrm{Na}_{2} \mathrm{SO}_{4}$ and $\mathrm{NaCl}$ : Oxidative damage and the role of polyphenols in antioxidant protection. AoB Plants 2014, 6, plu042. [CrossRef] [PubMed] 
78. Sekmena, A.H.; Türkan, I.; Takio, S. Differential Responses of Antioxidative Enzymes and Lipid Peroxidation to Salt Stress in Salt-Tolerant Plantago maritime and Salt-Sensitive Plantago media. Physiol. Plant. 2007, 131, 399-411. [CrossRef]

79. Winkel-Shirley, B. Biosynthesis of flavonoids and effects of stress. Curr. Opin. Plant Biol. 2002, 5, 218-223. [CrossRef]

80. Agati, G.; Azzarello, E.; Pollastri, S.; Tattini, M. Flavonoids as antioxidants in plants: Location and functional significance. Plant Sci. 2012, 196, 67-76. [CrossRef]

81. Vogt, T. Phenylpropanoid biosynthesis. Mol. Plant 2010, 3, 2-20. [CrossRef]

82. Rao, M.V.; Paliyath, G.; Ormrod, D.P. Ultraviolet-B- and ozone-induced biochemical changes in antioxidant enzymes of Arabidopsis thaliana. Plant Physiol. 1996, 110, 125-136. [CrossRef] [PubMed]

83. Ostrowski, M.; Ciarkowska, A.; Jakubowska, A. The auxin conjugate indole-3-acetyl-aspartate affects responses to cadmium and salt stress in Pisum sativum L. J. Plant Physiol. 2016, 191, 63-72. [CrossRef]

84. Higashi, Y.; Takechi, K.; Takano, H.; Takio, S. Maintenance of normal stress tolerance in the moss Physcomitrella patens lacking chloroplastic CuZn-superoxide dismutase. Am. J. Plant Sci. 2015, 6, 591-601. [CrossRef]

85. Migowska, N.; Stepnowski, P.; Paszkiewicz, M.; Golebiowski, M.; Kumirska, J. Trimethylsilyldiazomethane (TMSD) as a new derivatization reagent for trace analysis of selected non-steroidal anti-inflammatory drugs (NSAIDs) by gas chromatography methods. Anal. Bioanal. Chem. 2010, 397, 3029-3034. [CrossRef] [PubMed]

86. Campanella, J.J.; Ludwig-Müller, J.; Bakllamaja, V.; Sharma, V.; Cartier, A. ILR1 and sILR1 IAA amidohydrolase homologs differ in expression pattern and substrate specificity. Plant Growth Regul. 2003, 41, 215-223. [CrossRef]

87. Cohen, J.D.; Baldi, B.G.; Slovin, J.P. ${ }^{13}$ C6-[benzene ring]-indole-3-acetic acid. Plant Physiol. 1986, 80, 14-19. [CrossRef] [PubMed]

88. Heath, R.L.; Packer, L. Photoperoxidation in isolated chloroplasts. I. Kinetics and stoichiometry of fatty acid peroxidation. Arch. Biochem. Biophys. 1968, 125, 189-198. [CrossRef]

89. Singleton, V.L.; Rossi Jr., J. A. Colorimetry of total phenolics with phosphomolybdicphosphotungstic acid reagents. Am. J. Enol. Viticult. 1965, 16, 144-158.

90. Qureshi, M.I.; Abdin, M.Z.; Ahmad, J.; Iqbal, M. Effect of long-term salinity on cellular antioxidants, compatible solute and fatty acid profile of Sweet Annie (Artemisia annua L.). Phytochemistry 2013, 95, 215-223. [CrossRef] [PubMed]

91. Neuhoff, V.; Arold, N.; Taube, D.; Ehrhardt, W. Improved staining of proteins in polyacrylamide gels including isoelectric focusing gels with clear background at nanogram sensitivity using Coomassie Brilliant Blue G-250 and R-250. Electrophoresis 1988, 9, 255-262. [CrossRef] [PubMed]

92. Bortz, J.; Schuster, C. Statistik Für Human-und Sozialwissenschaftler; Springer: Berlin/Heidelberg, Germany, 2010; ISBN 9783642127700.

93. Horn, M.; Vollandt, R. Multiple Test- und Auswahlverfahren; Springer: Berlin/Heidelberg, Germany, 1991 ; ISBN 9783437205101. 